This is the final peer-reviewed accepted manuscript of:

"Light: a very peculiar reactant and product"

V. Balzani, G. Bergamini, P. Ceroni

Angew. Chem. Int. Ed. 2015, 54, 11320-11337

The final published version is available online at: https://doi.org/10.1002/anie.201502325

Rights / License:

The terms and conditions for the reuse of this version of the manuscript are specified in the publishing policy. For all terms of use and more information see the publisher's website. 


\section{Light: a very peculiar reactant and product}

\section{Vincenzo Balzani, ${ }^{1 *}$ Giacomo Bergamini, ${ }^{1}$ Paola Ceroni ${ }^{1}$}

${ }^{1}$ Dipartimento di Chimica "G. Ciamician”, Università di Bologna, via Selmi 2, 40126 Bologna, Italy. E-mail: vincenzo.balzani@unibo.it

\section{Graphical abstract}

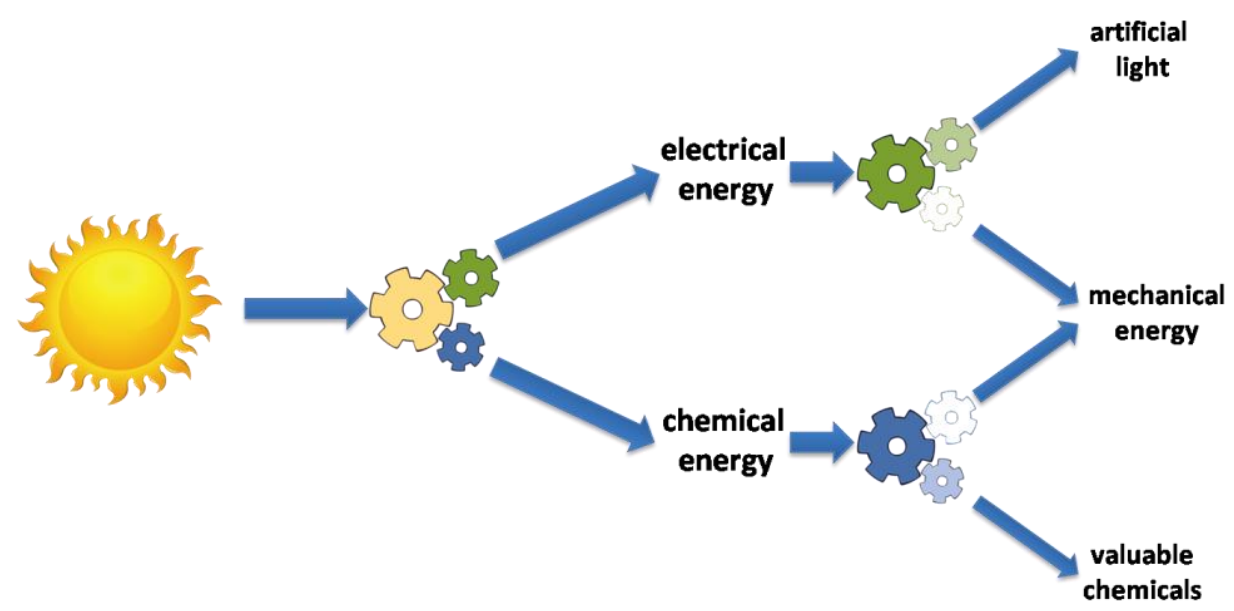

Light is the fastest way of transferring energy and information through space. In chemistry, light can perform the dual role of reactant and product. Sunlight, a really unique reactant (plentiful, inexhaustible, available everywhere and very energetic), represents our ultimate energy source. Chemists are engaged in designing systems for the conversion of light into electrical or chemical energy and of chemical and electrical energy into light, thereby contributing to create a more sustainable way of life. 


\begin{abstract}
Light is a mysterious physical entity that in chemical reactions can play the role of a reactant or a product. The most important font of reactant light is of course the Sun, our ultimate energy source. This ubiquitous reactant was involved in the appearance of life on the Earth and continues to supply us with practically all our food. Scientists are engaged to find efficient processes to convert sunlight into electrical and chemical energy and also to convert electrical and chemical energy into light. Most processes involving light as a reactant or as a product are based on the simplest chemical reaction: electron transfer. The conversion of light into electrical or chemical energy and of chemical and electrical energy into light requires the construction, starting from Earth' materials, of a variety of devices. Some of them are already in use, while others need to be improved concerning three key requirements: efficiency, stability, and scalability. Research in this field is contributing to the advancement of basic science and, more important, toward the creation of a sustainable world
\end{abstract}

Keywords: photochemistry, solar energy conversion, luminescence, photosensitizer, catalysis

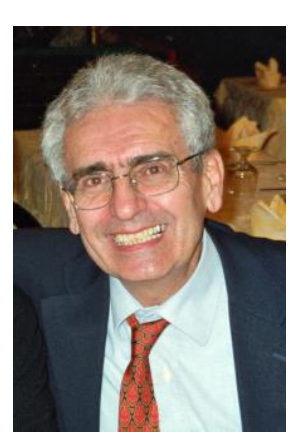

Vincenzo Balzani is Hemeritus Professor of Chemistry at the University of Bologna. He is fellow of the American Association for the Advancement of Science and the Accademia Nazionale dei Lincei. He has received many awards, including the Italgas European Prize for Research and Innovation and the Porter Medal on Photochemistry. His scientific activity is documented by three monographs and more than 550 papers in the fields of photochemistry, supramolecular chemistry, molecular devices and machines, and solar energy

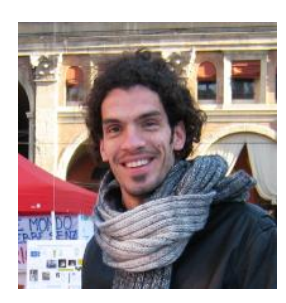
conversion.

Giacomo Bergamini got his $\mathrm{PhD}$ in 2007 in Chemical Science at the University of Bologna under the supervision of Prof. Vincenzo Balzani. He currently works in the "Photochemical Nanoscience Laboratory" in Bologna and he is co-author of more than 70 scientific papers in referred international journals.

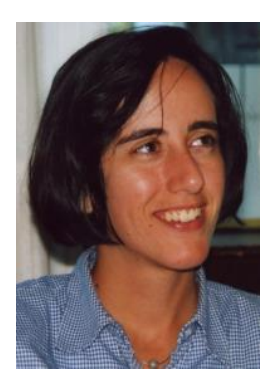

Paola Ceroni is Associate Professor at the University of Bologna. In 1998 she obtained her PhD degree in Chemical Sciences at the University of Bologna, after a period in the United States (Prof. Allen J. Bard's laboratory). Current research focuses on photoactive metal complexes, dendrimers and nanocrystals. She is coauthor of about 150 scientific papers and reviews. She is the principal investigator of an ERC Starting Grant for the development of hybrid materials for solar energy conversion. 


\section{Introduction}

Light can be viewed as a means (very fast, indeed!) of transferring energy and information through space. Photochemistry ${ }^{[1-3]}$ deals with both these phenomena. In this paper, we will discuss the energy aspects of the interaction between light and matter. The information aspect of light, which concerns several very important branches of photochemistry, will not be discussed.

As we will see, it is indeed possible to make use of light (particularly, sunlight) as a reactant in artificial chemical processes to produce electrical and chemical energy and it is also possible, by means of artificial chemical reactions, to convert electrical and chemical energy into light as a product. All these processes are based on the simplest chemical reaction: electron transfer.

\section{Light and redox reactions}

More than one hundred years ago, Giacomo Ciamician, the father of photochemistry, ${ }^{[3]}$ noticed that "light excitation is especially favorable to processes of oxidation and reduction". ${ }^{4]}$

The reason why light excitation can easily cause redox processes is well understood today. ${ }^{[3]}$ Electronically excited molecules are both better electron donors and better electron acceptors than the ground state species. Qualitatively, this can be realized looking at Figure 1: usually, light absorption promotes an electron from a lower energy to a higher energy orbital. The electron that has been promoted can be more easily removed, which means that the excited state has a smaller ionization potential than the ground state. At the same time, the promotion of an electron leaves behind a low-lying vacancy that can accept an electron, which means that the excited state has a higher electron affinity than the ground state.

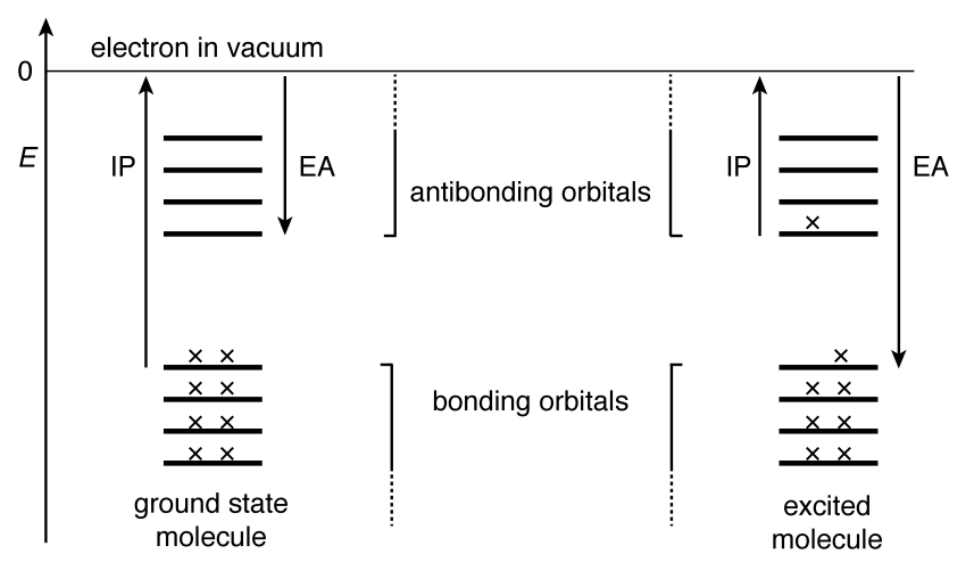

Figure 1. Orbital scheme useful to understand why an excited state is both a better electron donor and a better electron acceptor than the ground state species. ${ }^{[3]}$ 
Therefore light excitation is a remarkable, double face redox process since it generates a species capable to perform as both an oxidant and a reductant. A quantitative approach concerning the excited state redox properties is based on the extra amount of energy of the excited state compared to the ground state. ${ }^{[3]}$ In the case of a thermally equilibrated excited state and reversible redox processes, the excited state redox potentials are given by equations 1 and 2:

$$
\begin{aligned}
& E^{0}\left(\mathrm{~A}^{+} / * \mathrm{~A}\right)=E^{0}\left(\mathrm{~A}^{+} / \mathrm{A}\right)-E_{00}(* \mathrm{~A} / \mathrm{A}) \\
& E^{0}\left(* \mathrm{~A} / \mathrm{A}^{-}\right)=E^{0}\left(\mathrm{~A} / \mathrm{A}^{-}\right)+E_{00}(* \mathrm{~A} / \mathrm{A})
\end{aligned}
$$

$E_{00}(* \mathrm{~A} / \mathrm{A})$ is the one-electron potential corresponding to the electronic energy of the excited state (corresponding to the difference between the zero vibrational levels of ground and excited electronic states). It is worth noting that the term $E_{00}(* \mathrm{~A} / \mathrm{A})$ is related to the reactive excited state that does not necessarily coincide with the excited state populated by light absorption. It follows that for a reversible reaction

$$
* \mathrm{~A}+\mathrm{B} \rightarrow \mathrm{A}^{-}+\mathrm{B}^{+}
$$

the Gibbs free energy change can be obtained from the following equation:

$$
\Delta G_{\mathrm{et}}^{0}=N_{\mathrm{A}}\left\{e\left[E\left(\mathrm{~A} / \mathrm{A}^{-}\right)-E\left(\mathrm{~B}^{+} / \mathrm{B}\right)\right]+w\left(\mathrm{~A}^{-} \mathrm{B}^{+}\right)\right\}-E_{00}(* \mathrm{~A} / \mathrm{A})
$$

in which $N_{\mathrm{A}}$ is Avogadro's number, $e$ is the electronic charge, and $w$ is the electrostatic work term that accounts for Coulomb interactions between the partners after electron transfer (this term, to a first approximation, can be neglected). When irreversible processes are involved, the redox potential values are not experimentally available; although they can sometimes be estimated from other parameters, ${ }^{[5]}$ it is difficult to forecast whether the actual electron transfer process will take place under the experimental condition used.

In order to illustrate the above concepts and understand why they can be exploited in a variety of processes and applications, we take as an example the extensively used $\left[\mathrm{Ru}(\mathrm{bpy})_{3}\right]^{2+}$ complex. $^{[6]}$ Figure 2 summarizes the energetic links between the various forms of $\left[\operatorname{Ru}(b p y)_{3}\right]^{2+}$. Light excitation in the intense visible absorption band $\left(\lambda_{\max }=452 \mathrm{~nm}, \varepsilon_{\max } 14600 \mathrm{M}^{-1} \mathrm{~cm}^{-1}\right)$ leads to the lowest spin-allowed metal-to-ligand charge transfer $\left({ }^{1} \mathrm{MLCT}\right)$ excited state $\left(* *\left[\operatorname{Ru}(\mathrm{bpy})_{3}\right]^{2+}\right.$ in Figure 2), which undergoes very fast intersystem crossing to the lowest ${ }^{3}$ MLCT excited state $\left(*\left[\operatorname{Ru}(\mathrm{bpy})_{3}\right]^{2+}\right)$. This excited state lives long enough $(\tau=0.6 \mu \mathrm{s})$ to encounter other solute molecules before undergoing radiative or radiationless deactivation (in supramolecular systems, ${ }^{[7]}$ 
a suitable reaction partner may already be nearby $\left.*\left[\mathrm{Ru}(\mathrm{bpy})_{3}\right]^{2+}\right)$. The extra energy available to $*\left[\mathrm{Ru}(\mathrm{bpy})_{3}\right]^{2+}$ compared with the ground state amounts to $2.12 \mathrm{eV}$ and its reduction and oxidation potentials, obtained from equations 1 and 2 , are +0.84 and $-0.86 \mathrm{~V}$ (vs NHE, in water). It follows that $*\left[\operatorname{Ru}(\text { bpy })_{3}\right]^{2+}$ is at the same time a good electron acceptor (reaction 5), and a good electron donor (reaction 6):

$$
\begin{aligned}
& *\left[\mathrm{Ru}(\mathrm{bpy})_{3}\right]^{2+}+\mathrm{Q} \rightarrow\left[\mathrm{Ru}(\mathrm{bpy})_{3}\right]^{3+}+\mathrm{Q}^{-} \quad \text { oxidative quenching } \\
& *\left[\mathrm{Ru}(\mathrm{bpy})_{3}\right]^{2+}+\mathrm{Q} \rightarrow\left[\mathrm{Ru}(\mathrm{bpy})_{3}\right]^{+}+\mathrm{Q}^{+} \quad \text { reductive quenching }
\end{aligned}
$$

The two processes are potentially in competition, but usually only one is thermodynamically allowed for a given $\mathrm{Q}$. When both are thermodynamically allowed, kinetic factors establish which process wins the competition. ${ }^{[3]}$

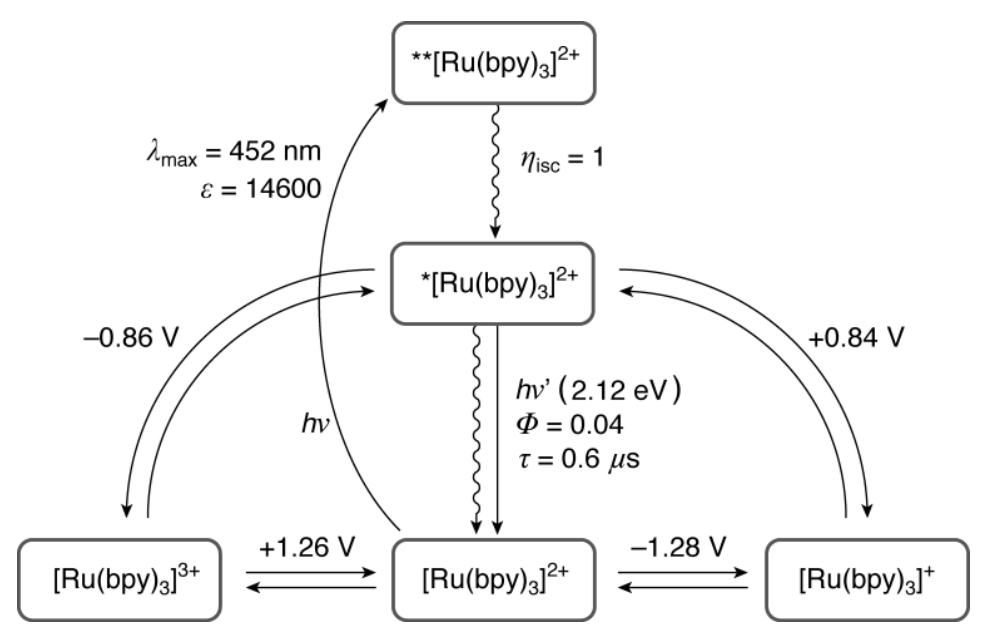

Figure 2. Molecular quantities of $\left[\mathrm{Ru}(\mathrm{bpy})_{3}\right]^{2+}$ relevant for electron transfer processes. ${ }^{[6]} * *\left[\mathrm{Ru}(\mathrm{bpy})_{3}\right]^{2+}$ indicates the spin-allowed excited state reached by light absorption and $*\left[\mathrm{Ru}(\mathrm{bpy})_{3}\right]^{2+}$ the lowest spinforbidden luminescent excited state ( $\left.{ }^{3} \mathrm{MLCT}\right)$. Reduction potentials are referred to NHE.

For reactions taking place in solution between an excited state and a solute Q (e.g., reactions 5 and 6, sometimes called dynamic quenching processes), the ratio of the excited state lifetime in the absence $\left(\tau^{0}\right)$ and presence $(\tau)$ of $\mathrm{Q}$ is given by: ${ }^{[3]}$

$$
\tau^{0} / \tau=1+\tau^{0} k_{\mathrm{q}}[\mathrm{Q}]
$$

In this equation, known as the Stern-Volmer equation, $k_{\mathrm{q}}$ is the rate of the quenching process and the product $\tau^{0} k_{\mathrm{q}}$ is called Stern-Volmer constant $\left(k_{\mathrm{SV}}\right)$. The maximum value of $k_{\mathrm{q}}$ is represented by the diffusion rate constant $\left(k_{\mathrm{d}}\right)$ in the solvent used. Assuming that the reaction occurs at its 
maximum rate, $k_{\mathrm{q}}=k_{\mathrm{d}}$, equation 7 can be employed to evaluate the smallest concentration of $\mathrm{Q}$ required to quench an excited state with a predetermined efficiency.

A scheme of the type of that shown in Figure 2 can be constructed, in principle, for any excited state of any molecule when the pertinent data are available. ${ }^{[3]}$ Therefore, photoexcitation affords chemists with a huge repertoire of strong oxidants and reductants, ${ }^{[1-3,8-11]}$ which, however, should be used with precaution because the necessary conditions of reversibility are often lacking in the reaction medium. Figure 3 shows the relationship between ground and excited state redox potentials for some compounds often used in redox processes involving excited states. In the case of metal complexes, by far the most common one, both the redox properties and the excited state energy can be fine- or coarse-tuned by changing the metal, the ligands and/or substituents on the ligand rings. For example, $*\left[\mathrm{Ru}(\mathrm{bpy})_{3}\right]^{2+}$ has a higher energy content than $*\left[\mathrm{Cr}(\mathrm{bpy})_{3}\right]^{2+}$, but the latter is a much stronger oxidant. $*\left[\mathrm{Ru}(\mathrm{bpy})_{2}(\mathrm{biq})\right]^{2+}(\mathrm{biq}=$ biquinoline) has a lower excited state energy $(736 \mathrm{~nm}, 1.68 \mathrm{eV})$ compared with $*\left[\mathrm{Ru}(\mathrm{bpy})_{3}\right]^{2+}$ and it is easier to reduce $(-0.37 \mathrm{~V}$ vs NHE). ${ }^{[8]}$ The excited state energy $2.34 \mathrm{eV}$ of $f a c-\left[\operatorname{Ir}(\mathrm{ppy})_{3}\right]$ moves to $2.76 \mathrm{eV}$ for $f a c-\left[\operatorname{Ir}\left(4^{\prime}, 6^{\prime}-\mathrm{F}_{2}-\right.\right.$ ppy $\left.)_{3}\right]$ and $2.64 \mathrm{eV}$ for $\left[\operatorname{Ir}(\mathrm{ppy})_{2}(\mathrm{CN})_{2}\right]^{-}$, while the ground state oxidation potential moves from + $0.77 \mathrm{~V}$ to $+1.29 \mathrm{~V}$ and $+1.42 \mathrm{~V}$ (vs SCE), respectively. ${ }^{[9,10]}$
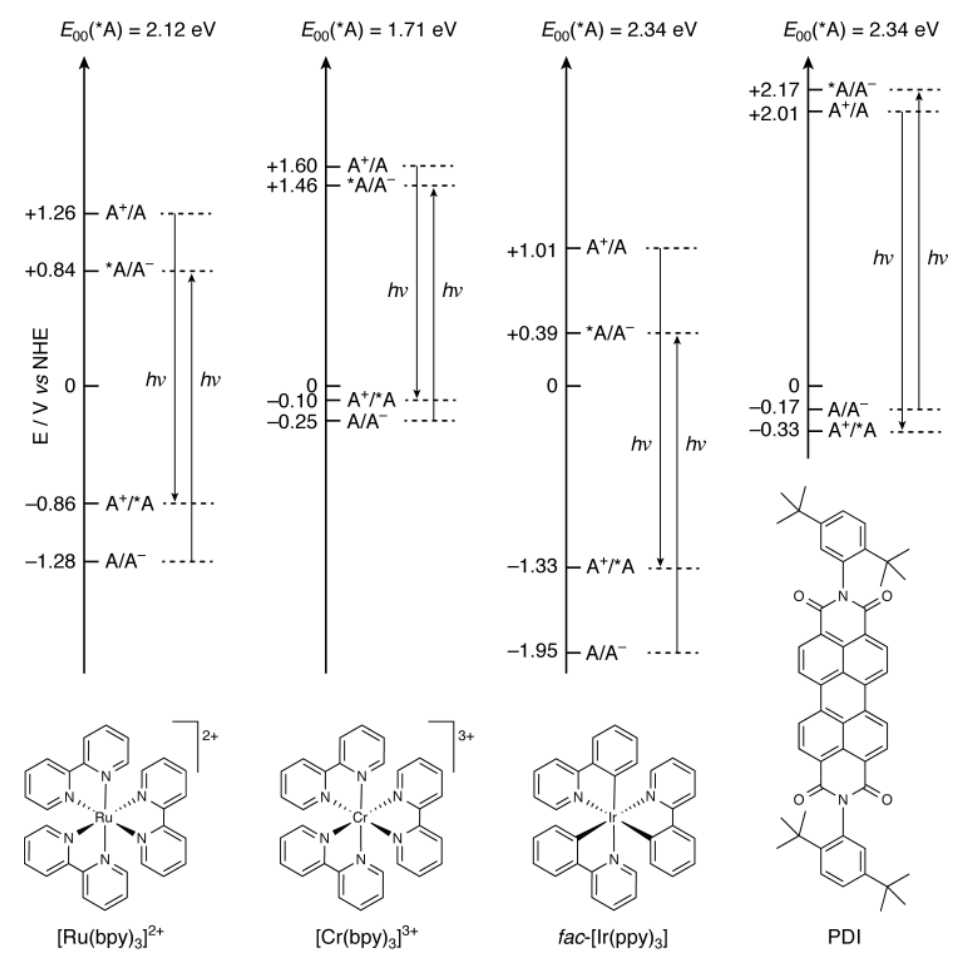

Figure 3 Relationship between ground and excited state redox potentials in a few compounds used in redox reactions involving excited states. 
The excited state redox properties of molecules, particularly of transition metal complexes like $\left[\mathrm{Ru}(\mathrm{bpy})_{3}\right]^{2+}$, are extensively used not only for energy conversion, but also for analytical purposes (see e.g., Section 6.2) and signal processing. ${ }^{[12,13]}$ For example, $\left[\mathrm{Ru}(\mathrm{bpy})_{3}\right]^{2+}$ can act both as a 4to-2 encoder and 2-to-4 decoder. ${ }^{[14]}$

\section{Interconversion between light and chemical or electrical energy}

In suitable systems, the above described relationship between excited state energy and redox potentials can be exploited to convert light energy into chemical or electrical energy and vice versa. ${ }^{[15]}$

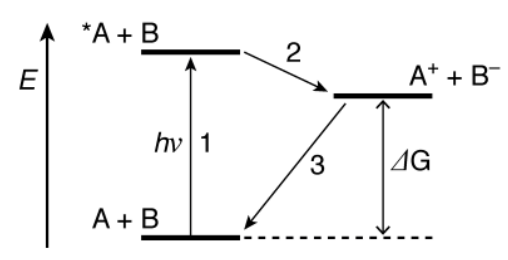

(a)

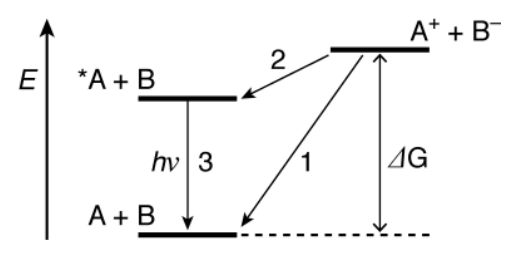

(b)

Figure 4. Schematic representation of the conversion of light into chemical or electrical energy (a) and of chemical or electrical energy into light (b) by electron transfer processes.

In Figure 4a, the light energy converted with formation of the $\mathrm{A}^{+}$and $\mathrm{B}^{-}$redox pair $(\operatorname{arrows} 1+2)$ can be exploited (arrow 3) as thermal energy or as electrical energy (if the back reaction is performed, e.g., in a fuel cell). Figure $4 \mathrm{~b}$ shows that the chemical energy of the $\mathrm{A}^{+}$and $\mathrm{B}^{-}$redox pair can be converted, in competition with the thermal process 1 , into light (arrows $2+3$ ), a process termed chemiluminescence; if one or both the reactants $\mathrm{A}^{+}$and $\mathrm{B}^{-}$are generated in situ by electrochemical oxidation of $\mathrm{A}$ and/or reduction of $\mathrm{B}$, electrical energy can be converted into light and the process is called electrochemiluminescence.

Of the utmost importance is the fact that, by using suitable compounds called photosensitizers (PS), interconversion between light and chemical or electrical energy can be obtained also with chemical systems that are not able to absorb or emit light. Such photosensitizers are sometimes called light absorption sensitizers (LAS) or light emission sensitizers (LES), depending on their specific role. ${ }^{[15]}$

For example, ${ }^{[16]}$ the reduction of methylviologen (1,1'-dimethyl-4,4'-bipyridinium dication, $\mathrm{MV}^{2+}$ ) by triphenylamine $\left(\mathrm{NPh}_{3}\right)$ is a strongly endergonic reaction and thus it does not occur in the dark: 


$$
\mathrm{MV}^{2+}+\mathrm{NPh}_{3} \mapsto \mathrm{MV}^{+}+\mathrm{NPh}_{3}{ }^{+} \quad(\Delta \mathrm{G}=+1.45 \mathrm{eV})
$$

In principle, it could be driven by visible light (i.e., by photons having an energy content higher than $1.45 \mathrm{eV})$. However, neither $\mathrm{MV}^{2+}$ nor $\mathrm{NPh}_{3}$ are able to absorb visible light. When $\left[\mathrm{Ru}(\mathrm{bpy})_{3}\right]^{2+}$ is present in the solution, it can be excited by visible light and its excited state reduces $\mathrm{MV}^{2+}$ to $\mathrm{MV}^{+}$. If the concentrations of $\mathrm{NPh}_{3}$ is sufficiently high, the reaction of $\left[\mathrm{Ru}(\mathrm{bpy})_{3}\right]^{3+}$ with $\mathrm{NPh}_{3}$ prevails over the back electron transfer reaction of $\left[\mathrm{Ru}(\mathrm{bpy})_{3}\right]^{3+}$ with $\mathrm{MV}^{+}$ and the net result of the experiment is the occurrence of reaction 8 , driven by the light absorbed by $\left[\mathrm{Ru}(\text { bpy })_{3}\right]^{2+}$ (Figure 5$)$.

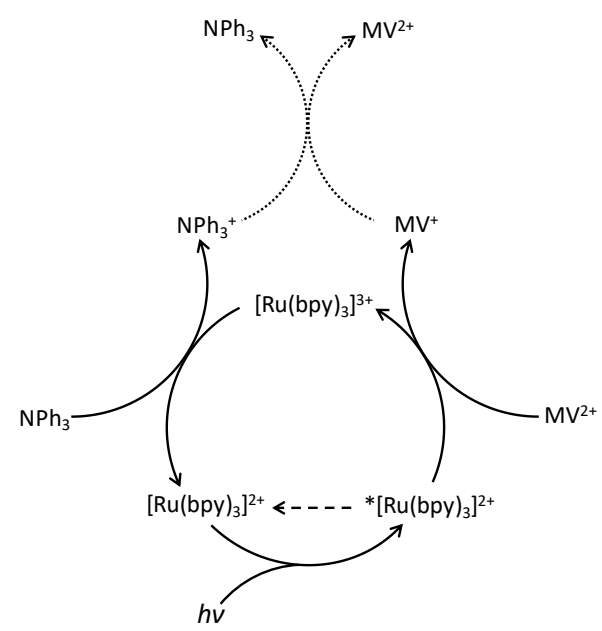

Figure 5. Conversion of light into chemical energy by using $\left[\mathrm{Ru}(\mathrm{bpy})_{3}\right]^{2+}$ as light absorption sensitizer (LAS). ${ }^{[16]}$ The dashed arrow indicates the photophysical deactivation of the excited state, which competes with its reaction with $\mathrm{MV}^{2+}$ and the dotted arrows indicate the back electron transfer reaction.

In such a system, the conversion of light into chemical energy is a transient result because of the occurrence of the fast back electron transfer reaction between the strong $\mathrm{MV}^{+}$reductant and the strong $\mathrm{NPh}_{3}{ }^{+}$oxidant.

In addition, the conversion of light energy into electrical energy is possible using $\left[\mathrm{Ru}(\mathrm{bpy})_{3}\right]^{2+}$ as LAS. Consider, for example, a cell consisting of two identical compartments separated by a sintered glass disk and containing a Pt electrode and an aqueous solution of $\left[\mathrm{Ru}(\mathrm{bpy})_{3}\right]^{2+}$ and $\mathrm{Fe}^{3+} \cdot{ }^{[17]}$ If one compartment is illuminated and the other one is kept in the dark, an electrical potential is generated which depends on the incident light intensity (photogalvanic effect, Figure 6): 


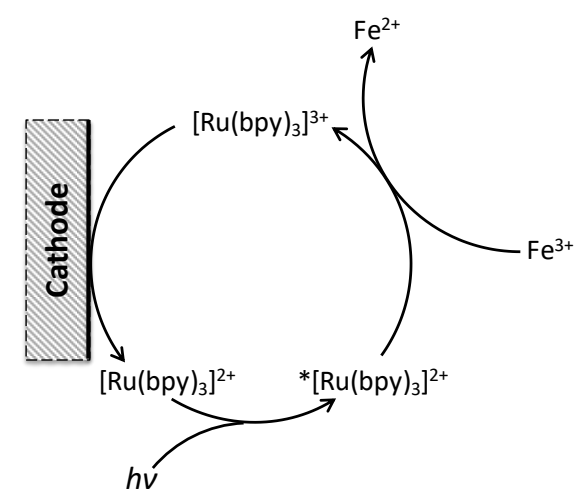

Figure 6. Illuminated compartment of a photogalvanic cell based on $\left[\mathrm{Ru}(\mathrm{bpy})_{3}\right]^{2+}$ as light absorption sensitizer (LAS). ${ }^{[17]}$ For details, see text.

An example of $\left[\mathrm{Ru}(\mathrm{bpy})_{3}\right]^{2+}$ playing the role of LES in the conversion of chemical energy into light is displayed in Figure 7. The customary laboratory reduction of lead dioxide by oxalate ions in acid media would be sufficiently exergonic to produce visible light, but it produces heat only:

$$
1 / 2 \mathrm{PbO}_{2}+1 / 2 \mathrm{C}_{2} \mathrm{O}_{4}{ }^{2-}+2 \mathrm{H}^{+} \rightarrow 1 / 2 \mathrm{~Pb}^{2+}+\mathrm{CO}_{2}+\mathrm{H}_{2} \mathrm{O} \quad(\Delta \mathrm{G} \sim-2 \mathrm{eV})
$$

However, when the reaction is carried out in the presence of $\left[\mathrm{Ru}(\mathrm{bpy})_{3}\right]^{2+}$, light emission is observed. ${ }^{[18]}$ The most likely reaction mechanism involves first the oxidation of $\left[\mathrm{Ru}(\mathrm{bpy})_{3}\right]^{2+}$ by $\mathrm{PbO}_{2}$ (reaction 10) and then the reduction of $\left[\mathrm{Ru}(\mathrm{bpy})_{3}\right]^{3+}$ by $\mathrm{C}_{2} \mathrm{O}_{4}{ }^{2-}$ in two steps (reactions 11 and 12) with formation of the luminescent $*\left[\operatorname{Ru}(\mathrm{bpy})_{3}\right]^{2+}$ excited state (Figure 7 ):

$$
\begin{aligned}
& {\left[\mathrm{Ru}(\text { bpy })_{3}\right]^{2+}+1 / 2 \mathrm{PbO}_{2}+2 \mathrm{H}^{+} \rightarrow\left[\mathrm{Ru}(\text { bpy })_{3}\right]^{3+}+1 / 2 \mathrm{~Pb}^{2+}+\mathrm{H}_{2} \mathrm{O}} \\
& {\left[\mathrm{Ru}(\text { bpy })_{3}\right]^{3+}+\mathrm{C}_{2} \mathrm{O}_{4}{ }^{2-} \rightarrow\left[\mathrm{Ru}(\text { bpy })_{3}\right]^{2+}+\mathrm{CO}_{2}+\mathrm{CO}_{2}{ }^{-}} \\
& {\left[\mathrm{Ru}(\text { bpy })_{3}\right]^{3+}+\mathrm{CO}_{2}{ }^{-} \rightarrow *\left[\mathrm{Ru}(\text { bpy })_{3}\right]^{2+}+\mathrm{CO}_{2}}
\end{aligned}
$$

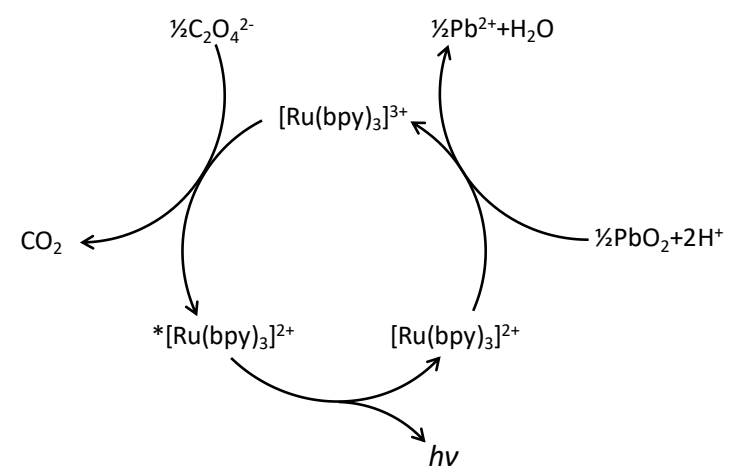


Figure 7. An example of conversion of chemical energy into light by using $\left[\mathrm{Ru}(\mathrm{bpy})_{3}\right]^{2+}$ as light emission sensitizer (LES). ${ }^{[18]}$ For details, see text.

A remarkable example of $\left[\mathrm{Ru}(\mathrm{bpy})_{3}\right]^{2+}$ playing the role of LES in the conversion of electrical energy into light is that illustrated by Figure $8 .{ }^{[19]}$ In acetonitrile solutions containing $\left[\mathrm{Ru}(\mathrm{bpy})_{3}\right]^{2+}$, switching the potential applied to a working electrode between the oxidation and reduction potentials of the complex causes formation of the reduced $\left[\mathrm{Ru}(\mathrm{bpy})_{3}\right]^{+}$and oxidized $\left[\mathrm{Ru}(\mathrm{bpy})_{3}\right]^{3+}$ species whose reaction is sufficiently exergonic to produce a ground $\left[\mathrm{Ru}(\mathrm{bpy})_{3}\right]^{2+}$ and an excited $*\left[\mathrm{Ru}(\mathrm{bpy})_{3}\right]^{2+}$ state, which undergoes light emission.

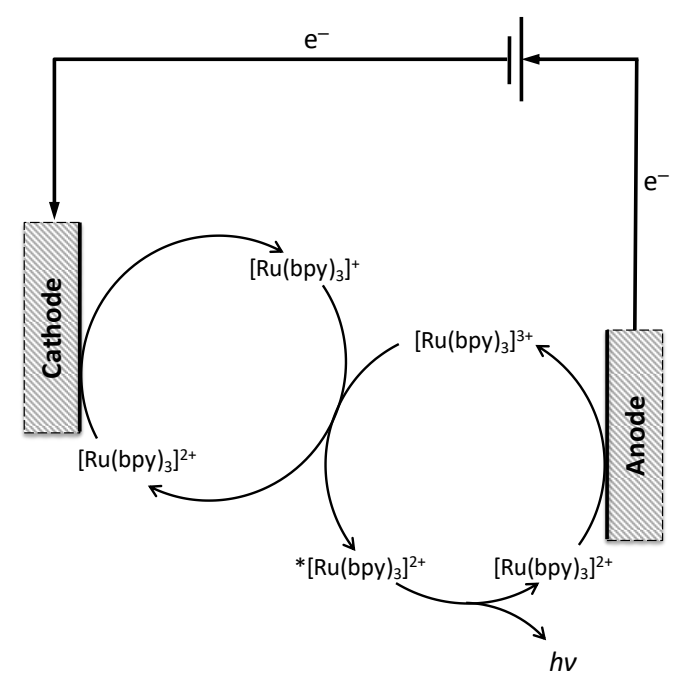

Figure 8. Conversion of electrical energy into light (electrochemiluminescence) by using $\left[\mathrm{Ru}(\mathrm{bpy})_{3}\right]^{2+}$ as a LES. ${ }^{[19]}$

\section{Conversion of solar energy into electrical energy}

\subsection{Inorganic solar cells (PV cells)}

Inorganic photovoltaic solar cells (usually called PV cells) are made of semiconducting materials consisting in doped silicon or combinations of elements such as gallium, arsenic, tellurium, copper or cadmium.

\subsubsection{Silicon PV cells}

In silicon solar cells (Figure 9), a slice of n-type material (e.g. phosphorus doped) is placed in physical contact with a slice of p-type (e.g. boron doped), so that the "free" electrons in the n-side will rush to fill the "holes" in the p-side. An electron migration over the p-n junction occurs, 
which creates a net negative charge on the p-doped material, counterbalanced by an identical positive charge on the n-doped material. This spontaneous process creates an electric field that, at a given point, stops electron flowing in one direction, thereby producing a diode. For silicon diodes, the built-in potential is approximately $0.6 \mathrm{~V}$.

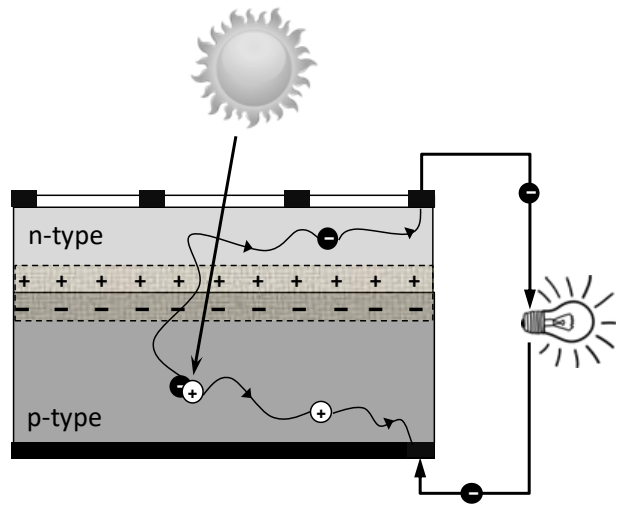

Figure 9. Conversion of light into electrical energy in a silicon photovoltaic cell.

When light excitation promotes an electron from the valence (VB) to the conduction band (CB) of p-side silicon in the vicinity of the junction, the electron will be attracted on the positive side of the field, flowing through the junction toward the n-type material. By connecting together the two sides of the cell, away from the junction, the electron will be forced to travel outside the cell, generating an electric current from the n-side to the p-side, from which useful work can be extracted.

Photons carrying energy below the band gap of the cell material are totally wasted while photons above the band gap can utilize only a portion of their energy to release electrons. Small band gap materials absorb a broader part of the solar spectrum, but at the expense of lowering the open circuit voltage $\left(\mathrm{V}_{\mathrm{oc}}\right)$; on the other hand, large band gap semiconductors sacrifice the low-energy wavelengths in the red part of the spectrum, thereby lowering the short circuit current $\left(\mathrm{J}_{\mathrm{sc}}\right)$. For a single junction PV cell, the optimal band gap is $\sim 1.4 \mathrm{eV}$, which yields a maximum $\eta$ of $33 \%{ }^{\text {[20] }}$

One of the most promising strategies to overcome the above limit and exploit the solar energy flow with higher efficiency is the use of the so-called multi-junction (or tandem) cells, in which two or more cell junctions are combined, each of which with a band gap optimized for a particular part of the solar spectrum. ${ }^{[21]}$

Over $80 \%$ of today's commercial solar cells are based on doped silicon in either single-crystal or polycrystalline form (sc-Si and poly-Si, respectively). The band gap of silicon is $1.1 \mathrm{eV}$ and the maximum theoretical efficiency of Si solar cells is about $30 \%$. The solar energy conversion 
efficiency of standard industrial cells is between 15 and $20 \%$, but a value of $25.6 \%$ has been reached at research level. ${ }^{[21]}$ Silicon solar cells are robust and reliable, but rather expensive, owing to the energy-intensive crystal growth and vapor deposition methods needed to make such cells.

\subsubsection{Non-silicon PV cells}

Among non-silicon semiconducting substances, a leading material is polycrystalline CdTe whose band gap of about $1.5 \mathrm{eV}$ is nearly optimally matched to the solar spectrum. This material is characterized by a high absorption coefficient $\left(>5 \times 10^{5} / \mathrm{cm}\right)$, which means that $\sim 99 \%$ of photons with energy greater than the band gap can be absorbed within $2 \mu \mathrm{m}$ of CdTe film (compared to 150-200 $\mu \mathrm{m}$ for Si PV). The conversion efficiency of CdTe solar cell has increased strongly in the last few years to reach $21 \%$ in $2014 .^{[21]}$

Another leading material is copper indium gallium di-selenide (CIGS), a polycristalline material with physical properties similar to CdTe, but a slightly smaller band gap of $1.3 \mathrm{eV}$. CIGS solar cells with conversion efficiencies $23.3 \%$ have been produced. ${ }^{\text {[21] }}$

CdTe and CIGS thin film photovoltaic technology is growing rapidly. Its major advantage is that the active material can be deposited as ink on flexible aluminum foils. A severe drawback of CdTe is that cadmium is one of the top six deadliest and toxic materials known. CdTe appears to be less toxic than elemental cadmium, and apparently these modules do not produce any pollutants during their operation. Another drawback is that tellurium is an extremely rare element. For these reasons, there is a race towards preparation of other suitable semiconducting materials such as $\mathrm{FeS}_{2}, \mathrm{CuO}$, and $\mathrm{Zn}_{3} \mathrm{P}_{2}{ }^{[22]}$

\subsection{Organic solar cells (OSCs)}

Organic solar cells (OSCs), sometimes indicated as plastic or polymer solar cells, are based on charge transfer occurring at the interface between two distinct materials (Figure 10), namely an electron-donor (D) and an electron-acceptor (A), which, at their contact surfaces, constitute the analogue of the "inorganic" semiconductor p-n junctions described above. The excited state generated by light absorption of either $\mathrm{D}$ (most commonly) or $\mathrm{A}$ is a molecular excited state, usually called 'exciton'. This is essentially an electron-hole pair that can either recombine to emit light or heat or, more usefully, can migrate to the interface and produce $\mathrm{D}^{+}$and $\mathrm{A}^{-}$species. Following excitation (usually to a singlet excited state) of D, the following chain of events can 
occur: (i) energy migration to nearby D species up to the interface region containing D and A species; (ii) formation of an excited charge-transfer (CT) state, $\mathrm{D}^{+} / \mathrm{A}^{-}$, in competition with energy transfer to a lower lying neutral (singlet or triplet) excited state of the system; (iii) thermal and/or electronic relaxation of the excited CT state; (iv) evolution of the excited CT state to a separated charge pair, with electron located in the acceptor material and hole in the donor.

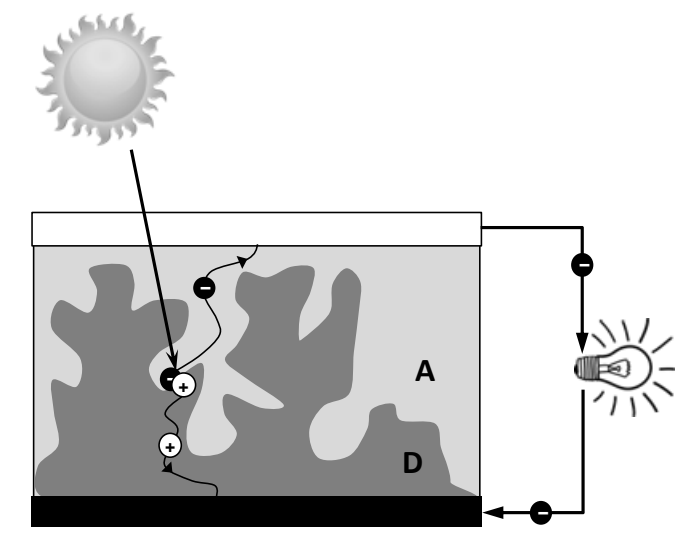

Figure 10. Scheme of OSCs. For details, see text.

The so-obtained charges eventually move to the respective electrodes, generating a photovoltaic current. In order to take advantage of enhanced dissociation at the donor-acceptor interface, excitons should be generated as close as possible to the heterojunction. Additionally, a continuous conducting pathway should exist for electrons and holes to reach the electrodes. OSCs are made with a disordered bulk heterojunction (BHJ), in which donor and acceptor are intimately mixed to form an interpenetrating phase network at the nanoscale level (Figure 10). Organic materials have relatively strong absorption coefficients (usually $\geq 10^{5} \mathrm{~cm}^{-1}$ ), thus considerable light absorption is achieved even with ultrathin devices $(<100 \mathrm{~nm})$. The most popular electron acceptor molecules utilized in organic solar cells are fullerene $\mathrm{C}_{60}$ and $\mathrm{C}_{70}$ derivatives, ${ }^{[23,24]}$ while organic conjugated polymers, e.g., P3HT (poly(3-hexylthiophene-2,5-diyl), ${ }^{[25]}$ are generally used as electron donors. The main advantages of organic photovoltaic devices are as follows: (i) low weight and flexibility of the PV modules; (ii) easy integration into other products; (iii) significantly lower manufacturing costs compared to conventional inorganic technologies; (iv) manufacturing of devices in a continuous process using state of the art printing tools; (v) short energy payback times and low environmental impact during manufacturing and operations.

The field of OSCs has undergone an impressive growth in recent years. ${ }^{[26]}$ Efficiency has reached $11 \%{ }^{[21]} \mathrm{A}$ drawback is that organic materials are susceptible to chemical, photochemical and physical degradation, for instance by the action of oxygen and moisture. 


\subsection{Dye-sensitized solar cells (DSSCs)}

Solar power can be converted directly into electrical power not only in solid state photovoltaic devices (Figures 9 and 10), but also in photoelectrochemical cells, often called Grätzel cells, which are based on sensitization of wide gap semiconductors by LAS capable of exploiting sunlight. ${ }^{\text {[27] }}$

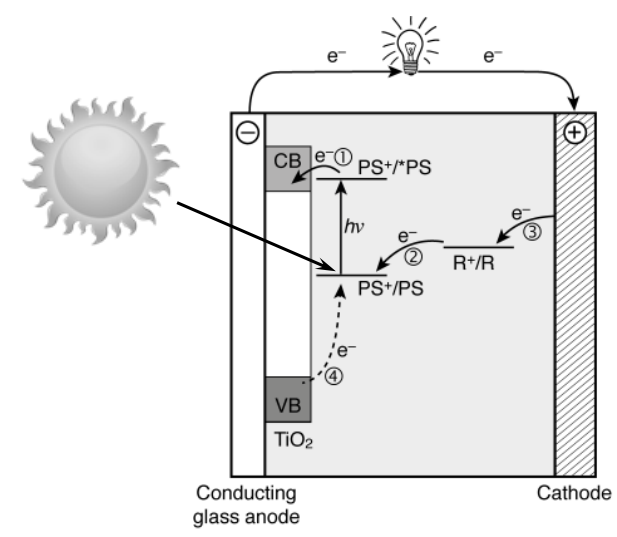

(a)

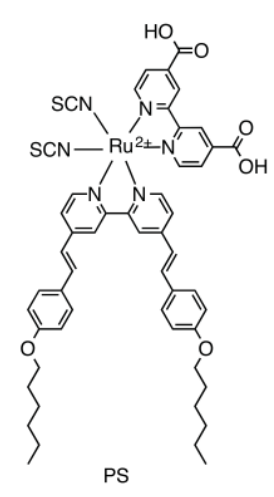

(b)

Figure 11. (a) Working principle of a dye-sensitized solar cell. PS is a photosensitizer linked to a semiconductor electrode and $\mathrm{R}$ is redox mediator molecule. (b) An example of a Ru-oligopyridine type photosensitizer.

The working principle of a DSSC is schematized in Figure 11a. The system comprises a nanocrystalline semiconductor $\mathrm{TiO}_{2}$ electrode of very high surface area and a counter electrode, immersed in an electrolyte solution containing a redox mediator (R). A photosensitizer (PS) is anchored in some way (usually, by $-\mathrm{COOH},-\mathrm{PO}_{3} \mathrm{H}_{2}$, or $-\mathrm{B}(\mathrm{OH})_{2}$ groups) to the semiconductor surface. Light is absorbed by the photosensitizer, whose excited state injects an electron into the conduction band of the semiconductor (step 1 in Figure 11a). The oxidized sensitizer is reduced by a redox mediator (step 2, in competition with back electron transfer, step 4), which then diffuses to discharge at the counter electrode (step 3). As a result, a photopotential is generated between the two electrodes under open-circuit conditions and a corresponding photocurrent can be obtained. A great number of photosensitizers, particularly of the Ru-polypyridine family, have been employed (see, e.g., Figure 11b). A variety of solvents of different viscosity and of redox mediators have been used, ${ }^{[28]}$ the most common being the $\mathrm{I}_{3}{ }^{-} / \mathrm{I}^{-}$couple in acetonitrile solution. As schematized in Figure 11a, in DSSC the absorption spectrum of the cell is separated from the band gap of the semiconductor, so the cell sensitivity can be more easily tuned to match the solar spectrum. The cell efficiency depends on the dynamics of the competing processes. An efficiency of $13 \%$ has been obtained by using an engineered porphyrin dye. ${ }^{[29]}$

Tandem solar cells in which the $\mathrm{TiO}_{2}$ dye-sensitized photoanode is coupled to a NiO dyesensitized photocathode have also been reported. ${ }^{[30]}$ 
A huge leap has been achieved in the last few years by using as photosensitizers artificial perovskite with the general formula $\left(\mathrm{CH}_{3} \mathrm{NH}_{3}\right) \mathrm{MX}_{3-\mathrm{x}} \mathrm{Y} \mathrm{x}(\mathrm{M}=\mathrm{Pb}$ or $\mathrm{Sn} ; \mathrm{X}, \mathrm{Y}=\mathrm{I}, \mathrm{Br}, \mathrm{Cl}){ }^{[31]}$ Such thinfilm devices can be considered, in some way, as an evolution of DSSCs. Perovskites exhibit intense absorption bands over a broader region of the solar spectrum. As a result, perovskite-based solar cells can be thinner than other types of cells. Moreover, the simplicity of making the photosensitizer material via liquid-phase chemical reactions and depositing it by methods such as spraying and spin coating may make it possible for solar-cell manufacturers to eventually replace clean rooms and sophisticated manufacturing equipment with simple bench top processes. The energy conversion efficiency of solar cells based on perovskites has reached $20.1 \% .^{[21]}$ The main concerns regard lead toxicity and cell durability. The use of $\left(\mathrm{CH}_{3} \mathrm{NH}_{3}\right) \mathrm{SnI}_{3}$ is a possible solution to the first issue. ${ }^{[32]}$ The inclusion of a thin layer of carbon nanotubes embedded in an insulating polymer improves perovskite cell resistance to humidity and thermal degradation. ${ }^{[33]}$

\section{Conversion of solar energy into chemical energy}

\subsection{Natural photosynthesis}

The natural photosynthetic process of green plants consists in the splitting of water by sunlight into oxygen, which is released into the atmosphere, and "hydrogen" which is not released in the atmosphere but instead is combined with carbon dioxide to produce organic compounds of various types (Figure 12). The burning of these compounds with oxygen either by respiration (food) or combustion (fossil fuels, wood, biomass) forms the original compounds (water and carbon dioxide) and releases the stored energy that originated from sunlight.

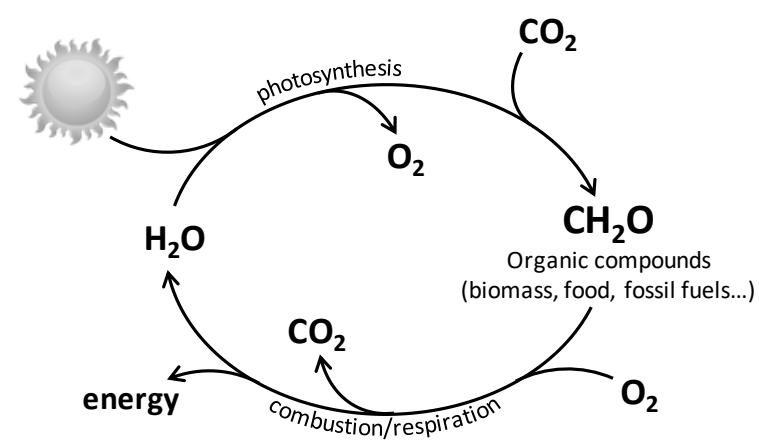

Figure 12. Schematic representation of natural photosynthesis, combustion, and respiration processes.

Since $\mathrm{H}_{2} \mathrm{O}$ and $\mathrm{CO}_{2}$ do not absorb sunlight, natural photosynthesis must be based on light excitation of photosensitizers. There exist several different photosynthetic organisms in nature. All use the same basic strategy: light is initially absorbed by antenna systems containing many 
chromophores, followed by energy transfer to a specialized reaction center protein in which the excited state energy is converted into chemical energy by means of one-electron transfer reaction. ${ }^{[34]}$ Figure 13 shows schematically the chain of electron transfer reactions taking place in bacterial photosynthesis after direct (or indirect, via energy transfer) excitation of the photosensitizer PS.

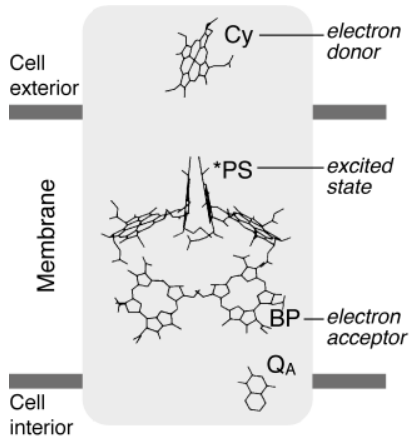

(a)

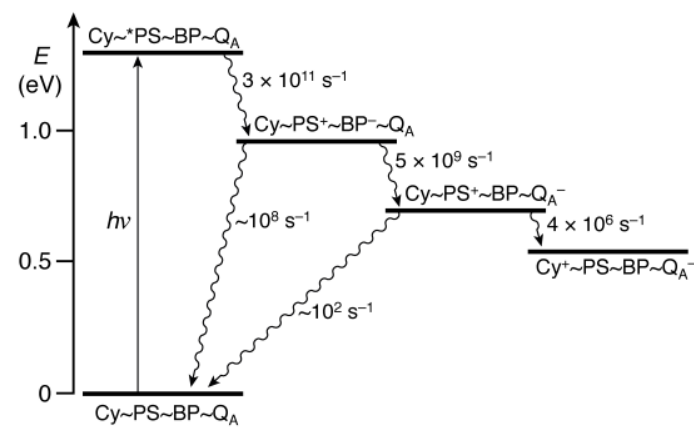

(b)

Figure 13. (a) A simplified view of the structure of the reaction center of Rhodopseudomonas viridis. (b) Energy-level diagram and rate constants of the electron-transfer steps involved in the charge-separation process. PS is a bacteriochlorophyl special pair. Adapted from ${ }^{[3]}$.

In green plant photosynthesis, two reaction centers, PSII and PSI, work in series so that two photons are needed to transfer one electron along the chain. The threshold energy is about 1.83 $\mathrm{eV}$ (680 $\mathrm{nm}$ light). The primary photoinduced charge separation reaction taking place in PSII is channeled by successive electron transfer processes towards generation of kinetically stable final products, $\mathrm{O}_{2}$ and "fixed" $\mathrm{CO}_{2}$ (e.g., carbohydrates). Oxygen evolution is mediated by the oxygenevolving catalyst (OEC), a cluster containing four manganese atoms and a calcium atom. ${ }^{[35,36]}$ The OEC accumulates, from four successive one-electron charge-separation processes, four holes that are used to oxidize two water molecules in a four-electron process. The corresponding reducing equivalents are transported by quinones to PSI where each of them is successively excited by a photon absorbed by a chlorophyll molecule, so as to have enough energy to drive the reduction of carbon dioxide. The efficiency of photosynthesis is very low (vide infra). ${ }^{[34,37,38]}$

\subsection{Artificial photosynthesis}

\subsubsection{General principles}


Generally speaking, a useful fuel is a chemical reductant that can be transported, stored and used on demand by reaction with oxygen from the air, with concomitant energy release. The production of fuels by non-biological photochemical reactions (artificial photosynthesis) was first anticipated by Giacomo Ciamician about one century ago. ${ }^{[39]}$ The studies on artificial photosynthesis are currently concentrated on using sunlight to reduce carbon dioxide in aqueous solution to CO, ethanol or methane (see, e.g., reaction 14$),{ }^{[40-42]}$

$\mathrm{CO}_{2}+2 \mathrm{H}_{2} \mathrm{O}+8 \mathrm{~h} v$ (sunlight) $\rightarrow \mathrm{CH}_{4}+2 \mathrm{O}_{2} \quad \Delta \mathrm{G}^{\circ}=8.30 \mathrm{eV}$

or to split water into molecular hydrogen and molecular oxygen:

$2 \mathrm{H}_{2} \mathrm{O}+4 \mathrm{~h} v$ (sunlight) $\rightarrow 2 \mathrm{H}_{2}+\mathrm{O}_{2} \quad \Delta \mathrm{G}^{\circ}=4.92 \mathrm{eV}$

Since carbon dioxide reduction is more difficult from a kinetic viewpoint and, if needed, can also be performed in a thermal reaction with molecular hydrogen, the attention of most scientists is focused on the photochemical water splitting (reaction 15).

The electronic absorption spectrum of water does not overlap the emission spectrum of the sun, so that direct water dissociation by sunlight cannot take place. ${ }^{[43]}$ From the thermodynamic viewpoint, the most convenient process for splitting water by solar energy is that involving the evolution of molecular oxygen and molecular hydrogen from liquid water (reaction 16), whose low energy thermodynamic threshold $(1.23 \mathrm{eV})$ in principle allows conversion of about $30 \%$ of the solar energy. Of course, a suitable photosensitizer should be used. Furthermore, water splitting involves two multielectron transfer reactions (reactions 17 and 18), the second one involving four-electron oxidation of two water molecules:

$1 / 2 \mathrm{H}_{2} \mathrm{O} \rightarrow 1 / 2 \mathrm{H}_{2}+1 / 4 \mathrm{O}_{2} \quad \Delta \mathrm{G}^{0}=1.23 \mathrm{eV}$

$2 \mathrm{H}_{2} \mathrm{O}+2 \mathrm{e}^{-} \rightarrow \mathrm{H}_{2}+2 \mathrm{OH}^{-} \quad \mathrm{E}^{0}(\mathrm{pH} 7)=-0.41 \mathrm{~V}$ vs NHE

$2 \mathrm{H}_{2} \mathrm{O} \rightarrow \mathrm{O}_{2}+4 \mathrm{H}^{+}+4 \mathrm{e}^{-} \quad \mathrm{E}^{0}(\mathrm{pH} 7)=+0.82 \mathrm{~V}$ vs NHE

Given that in a photochemical process each photon can transfer only one electron, ${ }^{[3]}$ two catalysts must be present in a water splitting system: one should collect electrons to produce molecular hydrogen and the other one should collect holes (positive charges) to produce molecular oxygen. This means that oxygen evolution requires four successive photoinduced electron-transfer steps 
(threshold: $1.23 \mathrm{eV}$ ), coupled with proton transfer (proton-coupled electron-transfer processes, PCETs $),{ }^{[44,45]}$ as it happens in the OEC of the natural photosynthetic system.

Artificial photosynthetic systems for water splitting require a very precise organization of different components (see, e.g., Figure 14) in the dimensions of space (location of the components), energy (excited state energies and redox potentials), and time (rates of competing processes).

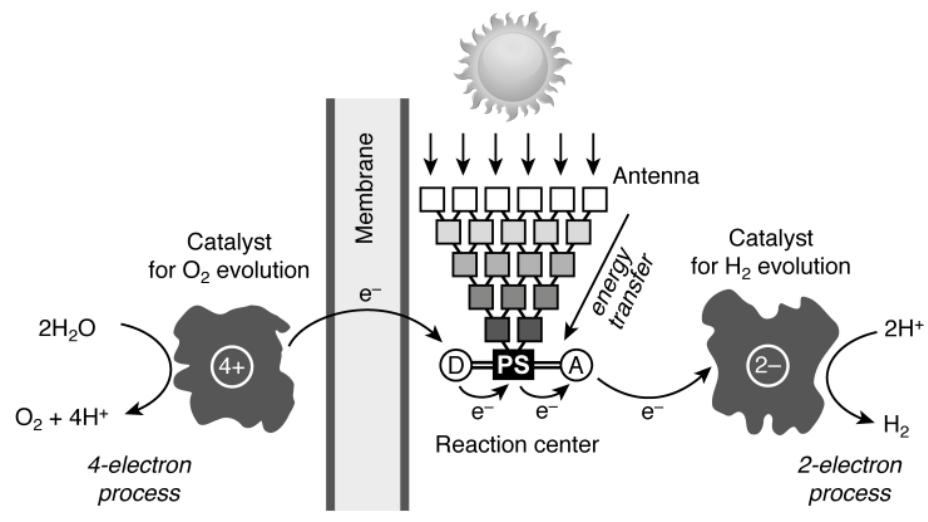

Figure 14. Schematic representation of the strategy for photochemical water splitting (artificial photosynthesis). Five fundamental components can be recognized: an antenna for light harvesting, a charge-separation triad D-P-A, a catalyst for hydrogen evolution, a catalyst for oxygen evolution, and a membrane separating the reductive and the oxidative processes. Adapted from ${ }^{[3]}$.

Through decades of sustained effort, substantial progress has been made on developing some essential components like antenna systems, ${ }^{[46]}$ reaction centers, ${ }^{[47,48]}$ homogeneous ${ }^{[49,50]}$ and heterogeneous ${ }^{[51]}$ multieletron catalysts, and semipermeable separators. ${ }^{[52]}$

While at the beginning it was thought that water splitting could be achieved by using homogeneous systems that is aqueous solutions of the needed molecular components with the aid of colloidal catalysts, it is now believed that practical systems should be based on photoactivation of solid state semiconductor materials, as described in Sections 5.2.2 and 5.2.3.

\subsubsection{Semiconductor-based photocatalytic systems $(P C)$ and photoelectrochemical cells (PEC)}

Irradiation of a semiconductor with photons having energy equal to or greater than its band gap promotes an electron $\left(\mathrm{e}^{-}\right)$to the conduction band (CB), with concomitant formation of a hole $\left(\mathrm{h}^{+}\right)$in the valence band (VB) (Figure 15). ${ }^{[53-55]}$ Electrons and holes migrate, thanks to band bending, to the surface of the semiconductor where charges can drive thermodynamically allowed reduction and oxidation reactions. 


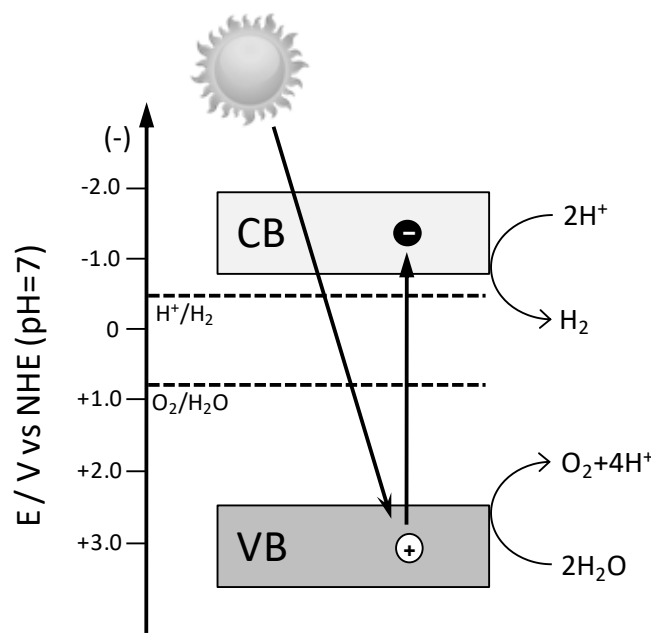

Figure 15. Fundamental steps for water splitting by solid-state photocatalysis. For simplicity, band bending and catalysts for water oxidation and water reduction are not shown.

To achieve photocatalytic water splitting using a single photocatalyst, the band gap of the semiconductor must straddle the reduction and oxidation potentials of water, which are $-0.41 \mathrm{~V}$ and $+0.82 \mathrm{~V}$ vs NHE, respectively, at pH 7 (reactions 17 and 18). The pioneering experiment on water splitting by irradiation of a semiconductor was performed in 1972 by using $\mathrm{TiO}_{2 .}{ }^{[56]}$ The energy gap of $\mathrm{TiO}_{2}$, however, corresponds to a threshold of $390 \mathrm{~nm}$, which means that visible light, and thus sunlight, is almost useless. Several hundreds semiconductors have been investigated in the last three decades, but presently no single material meets the requirements needed for practical applications: suitable band gap, matching energy band for $\mathrm{H}_{2}$ and $\mathrm{O}_{2}$ evolution, high efficiency and reasonable stability in aqueous solution. ${ }^{[54]}$

The photocatalytic activity can be enhanced by depositing catalysts (often called co-catalysts) for water oxidation (e.g., $\mathrm{RuO}_{2}$ nanoparticles) and water reduction (e.g., Pt nanoparticles) on the semiconductor surface. Unfortunately, the best catalysts are all composed by precious metals. Presently, much effort is thus directed towards the discovery of abundant, environmental friendly, inexpensive and highly efficient catalysts. ${ }^{[57]}$

The solar energy conversion efficiency depends on the efficiencies of light absorption, charge separation, charge migration, and charge utilization for $\mathrm{H}_{2}\left(\right.$ or $\left.\mathrm{O}_{2}\right)$ generation. ${ }^{[54,55]}$ The solar-tohydrogen ( $\mathrm{STH})$ efficiency is defined as the ratio between output energy as $\mathrm{H}_{2}$ and energy of incident solar light. Usually, comparisons among different systems are made on the basis of the incident photon-to-current efficiency (IPCE) and the apparent quantum yield (AQY). IPCE is defined as the ratio of the number of electrons passing through an external circuit as a photocurrent to the number of photons irradiating a photoelectrode. AQY is given by the ratio of the number of evolved molecules multiplied by the number of electrons involved in the 
photocatalytic reaction (e.g., two for $\mathrm{H}_{2}$ evolution) and the number of incident photons (the number of absorbed photons is difficult to determine due to light scattering). Both IPCE and AQY depend on the irradiation wavelength and thus they are usually determined under monochromatic irradiation.

In many cases the experiments have been performed in the presence of sacrificial reductants or oxidants to test the stability of the semiconductor and to optimize the occurrence of hydrogen or oxygen evolution. Overall water splitting by using visible light has so far been achieved only with a few systems. Recently, cobalt(II) oxide (CoO) nanoparticles have been found to carry on overall water splitting with a solar-to-hydrogen efficiency of around $5 \% .{ }^{[58]}$ Unfortunately, the catalyst undergoes photodegradation in a relatively short time.

Systematic studies have pointed out that efficient water splitting by sunlight should be based not only on more suitable semiconductors and catalysts, but also on appropriate strategic approaches, such as: ${ }^{[54]}$

(i) the help of an external power input with semiconductors playing the role of photocathode, or photoanode, or both (photoelectrochemical cells, PEC);

(ii) band gap engineering, by using proper dopants, introducing defects in the semiconductors crystals, or fabricating multi-component semiconductors through solid state reactions;

(iii) use of nanocrystals, nanosheets, one dimensional nanostructures and mesoporous structures;

(iv) bionic engineering based on the knowledge of the structure and function of key components and processes of natural photosynthesis.

Green plant photosynthesis has also inspired the so-called Z-scheme for water splitting, ${ }^{[59]}$ which is based on the use of two different photocatalysts, one suitable for $\mathrm{H}_{2}$ generation and the other one for $\mathrm{O}_{2}$ generation, connected by an electron mediator (Figure 16). ${ }^{[54,55]}$

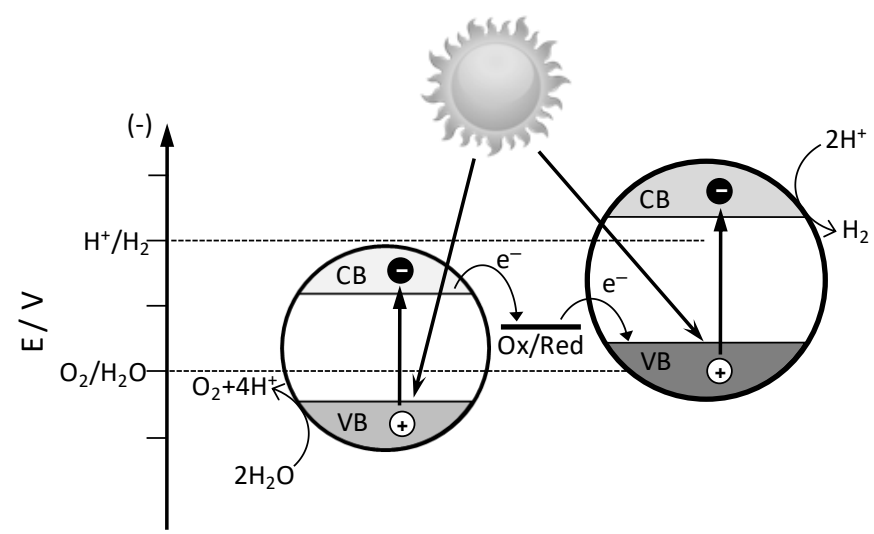

Figure 16. Schematic diagram showing a PC cell based on the Z-scheme. 
The Z-scheme is useful not only because it allows using many narrow band gap semiconductors, but also because it involves the formation of separated reduction and oxidation sites in two different photocatalysts, thereby avoiding the occurrence of surface back reactions. Besides liquid state Z-scheme systems like that illustrated in Figure 16, all-solid-state Z-schemes and direct Zschemes have been developed. An example of all-solid-state system is made of a $\mathrm{CdS} / \mathrm{Au} / \mathrm{TiO}_{2}$ nanojunction in which a $\mathrm{CdS}$ reduction site is connected by $\mathrm{Au}$ to a $\mathrm{TiO}_{2}$ oxidation site. ${ }^{[60]} \mathrm{An}$ example of direct $\mathrm{Z}$-scheme is given by a heterostructure made of $\mathrm{BiVO}_{4}$ and $\mathrm{Rh}-\mathrm{SrTiO}_{3}$ nanowires for overall water-splitting, where $\mathrm{BiVO}_{4}$ nanowires act as a photoanode for water oxidation and $\mathrm{Rh}_{-} \mathrm{SrTiO}_{3}$ nanowires work as a photocathode for water reduction. ${ }^{[61]}$ Catalysts, surfaces, and junctions are also the object of accurate engineering studies. ${ }^{[54]}$

Evolution of semiconductor photocatalysis for water splitting has led to the "artificial leaf" [62] consisting of a triple junction amorphous $\mathrm{Si}$ (3jn-a-Si) solar cell, a cobalt phosphate catalyst (CoP) for oxygen evolution and a NiMoZn catalyst for hydrogen evolution. When the wireless $\mathrm{CoP}|3 \mathrm{jn}-\mathrm{a}-\mathrm{Si}| \mathrm{NiMoZn}$ wafer is immersed in an open container of water with electrolyte and illuminated with sunlight, $\mathrm{O}_{2}$ and $\mathrm{H}_{2}$ evolve, respectively, from the anode and the cathode of the wireless cell at a solar-to-hydrogen efficiency of $2.5 \%$. Recently, a low-cost, not fully stable water-splitting cell combining two pervoskite solar cells and a bifunctional earth-abundant catalyst has displayed STH an efficiency of $12.3 \% .^{[63]}$

Constraints toward industrial application of water splitting arise from three key requirements: efficiency, stability, and scalability. ${ }^{[64]}$ The major challenge is not about finding new ideas, but rather on establishing whether or not the available model systems can be developed in a cost effective way at the terawatt scale. Nowadays, the technology available can at best be classed to be in the early Research \& Development stage. ${ }^{[65]}$

\subsubsection{Dye-sensitized photoelectrochemical cells (DSPECs)}

Dye-sensitized solar cells (Section 4.3) can be modified to obtain dye-sensitized photoelectrochemical cells (DSPECs) capable of exploiting sunlight to perform water splitting or other endoergonic reactions. ${ }^{[66]}$ DSPECs differ from PECs because light absorption and charge carrier transport are separated, and from DSSC because of the presence, in the anodic and/or cathodic compartments, of multielectron transfer catalysts capable of accumulating, respectively, holes and electrons generated by the photoinduced charge-separation process and use them to perform the desired endergonic reaction. 
Figure 17 shows the case of water splitting, obtained with the help of a small potential electric bias, in a DSPEC in which a nanoparticulate $\mathrm{TiO}_{2}$ photoanode is sensitized by a ruthenium polypyridine complex. ${ }^{[67]}$

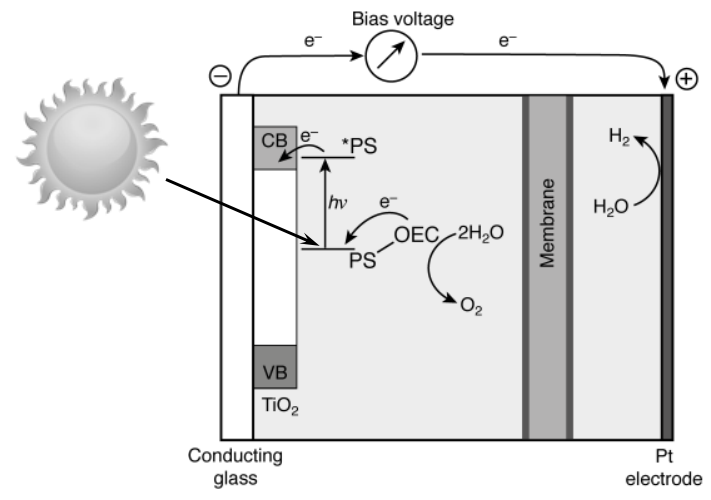

(a)

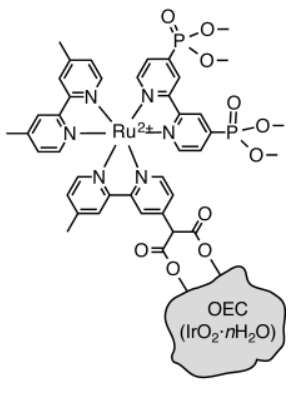

(b)

Figure 17. (a) Water splitting, obtained with the help of a small potential electric bias, in a DSPEC in which a nanoparticulate $\mathrm{TiO}_{2}$ photoanode is sensitized by a ruthenium polypyridine complex shown in (b). ${ }^{[67]}$

To improve the efficiency, an electron transfer mediator has been covalently bound to an $\mathrm{IrO}_{2}$ nanoparticle, coadsorbed on the $\mathrm{TiO}_{2}$ electrode with a $\mathrm{Ru}(\mathrm{II})$ photosensitizer. ${ }^{[68]}$

Molecular catalysts are attractive candidates with great potential for water splitting by the PEC cells, because their chemical structures can be easily modified and the related reaction mechanisms can be studied in detail. ${ }^{[66]}$

For more efficient use of sunlight photoanodes and photocathodes can be combined in a tandem approach, as already discussed for DSSCs (Section 4.3). In principle, one could couple water oxidation at the photoanode and $\mathrm{CO}_{2}$ reduction at the photocathode with formation of oxygen and methane. ${ }^{[69]}$ DSPECs represent, indeed, an interesting approach toward artificial photosynthetic processes. Their performance, however, is presently limited by instability, low efficiency, and small turnover of the catalysts.

\subsection{What's the best way to make use of sunlight?}

The yearly averaged solar power striking the Earth's surface is about $170 \mathrm{~W} / \mathrm{m}^{2}$. Therefore, each square meter of Earth's surface is a potential source of energy. To make use of it, we need to convert solar power into the four energy forms we use every day: food, electricity, fuels and heat. 
Conversion of sunlight into low temperature heat is an easy task. ${ }^{[70]}$ Conversion of sunlight into electricity and fuels needs complex processes as described above. An interesting question then arises: what's the best way to make use of sunlight? ${ }^{[37,71]}$

Natural photosynthesis converts light energy into the chemical energy contained in plant biomass, which is at the basis of the food chain. The threshold energy to obtain the photochemistry-driving excited state in green plant photosynthesis is about $680 \mathrm{~nm}(1.83 \mathrm{eV})$ and the two photosystems PSII and PSI work in series, ${ }^{[34]}$ so that two photons are needed to move an electron/proton from water to carbon dioxide. Taking into account leaf reflectivity and saturation effects, the maximum efficiency for the conversion of sunlight to stored chemical energy (dry carbon matter) is about $4.5 \%$. ${ }^{[38]}$ Losses caused by photodamage, reproduction and survival of the photosynthetic organisms further reduce the efficiency. In fact, even under the most favorable conditions crops produce biomass at efficiencies less than $1 \%$, and often as low as $0.1 \%$. Improving photosynthesis by synthetic biology techniques is not expected to change substantially the overall efficiency. ${ }^{\text {[37,71] }}$ Biomass, the end product of photosynthesis, can be used to satisfy three fundamental needs of mankind: food, energy and valuable materials. ${ }^{[70]}$ In recent years, the use of biomass to produce fuels (biofuels) has increased. Biogas, a mixture of $\mathrm{CH}_{4}$ and $\mathrm{CO}$, can be obtained from any type of organic matter (including sewage sludge and animal wastes). Liquid biofuels (bioethanol, biodiesel) are essentially produced by conventional agriculture resources (edible feedstocks) rich in carbohydrates such as sugarcane, corn, wheat, sugar beet.

It has been calculated that the energy of sunlight that is stored in biodiesel is less than $0.1 \%$, and that for bioethanol and biogas are around $0.2 \%$ and $0.3 \%$, respectively. ${ }^{[37]}$ These values, however, even do not take into account that a substantial fraction of the energy stored in a biofuel had to be invested in order to produce the biomass (plowing, synthesizing fertilizers and pesticides, irrigating, transporting). For corn, it has been estimated that the energy footprint is at least $25 \%$ of its energy content. ${ }^{[72]}$ Other energy must also be invested in the conversion of biomass into the biofuel. It follows that the ratio between energy returned on energy invested (EROEI) for biofuel is often close or even smaller than 1. Therefore, the production of biofuels constitutes an extremely inefficient use of the $170 \mathrm{~W}$ per square meter solar energy flux. Furthermore, the production and use of biofuels is not $\mathrm{CO}_{2}$-neutral as often claimed, but actually makes the climate issue worse. ${ }^{[70,73]}$ Finally, generation of biofuels from edible feedstocks is in competition with food production.

Waiting for substantial progress of artificial photosynthesis towards higher efficiency, stability, and scalability, ${ }^{[54,64,65]}$ there is no doubt that the best way to make use of sunlight is photovoltaics. The $15-20 \%$ conversion efficiency of solar energy into electric energy of commercial PV cells, which 
are reliable and stable for about 30 years, is at least two orders of magnitude larger than the conversion efficiency of sunlight into biofuels. Furthermore, the estimated EROEI of photovoltaics is significantly increasing. ${ }^{[7,75]}$ For transportation, the drawback of storing electric energy in batteries is more than compensated by the about four times higher efficiency of electric engines compared with internal combustion engines. Another advantage of PV solar energy conversion is that electrical energy can be used to generate hydrogen via electrolysis. ${ }^{[70,71]}$ Using a commercial PV cell with $18 \%$ conversion efficiency and a commercial electrolyzer the efficiency for water splitting is around $10-12 \%$.

\section{Conversion of chemical and electrical energy into light}

\subsection{Chemiluminescence and bioluminescence}

A chemiluminescent process is a chemical reaction in which light is generated as a product. This happens, for example, in all combustion reactions. Light emission implies the formation of an excited state as a primary product, which then undergoes radiative deactivation (Figure $4 \mathrm{~b}$ ). Chemiluminescent reactions are used for a variety of analytical purposes ${ }^{[76]}$ and find commercial applications as light sticks, commonly used for recreation and fishing. Light can also be generated by chemical reactions in living systems (bioluminescence). The emission of visible light by animals and plants is indeed a widespread and fascinating phenomenon in the living world. ${ }^{\text {[7] }}$ The simplest chemiluminescent reactions are those concerning outer-sphere electron transfer processes, in which the two species simply exchange an electron without undergoing decomposition (Figure 4.b). As shown in Section 3, chemiluminescence can be sensitized by a suitable LES. $\left[\mathrm{Ru}(\mathrm{bpy})_{3}\right]^{2+}$, the main character of several sections of this paper, can play this role (Figure 7). The most curious process in which $\left[\mathrm{Ru}(\mathrm{bpy})_{3}\right]^{2+}$ performs as a LES is the oscillating Belousov-Zhabotinskii reaction (artificial firefly). ${ }^{[78]}$

\subsection{Electrochemiluminescence}

Electrochemiluminescence (ECL) can be obtained by two principal methods: ${ }^{[19,79]}$

(i) Annihilation pathway, as discussed, for example, in Section 3, Figure 8.

(ii) Co-reactant pathway: besides the potentially luminescent compound, e.g., $\left[\mathrm{Ru}(\mathrm{bpy})_{3}\right]^{2+}$, the solution contains a co-reactant, e.g. tripropylamine (TPrA). Different mechanisms have been proposed for this system. The most likely one is that shown in Figure 18. ${ }^{[79]}$ 


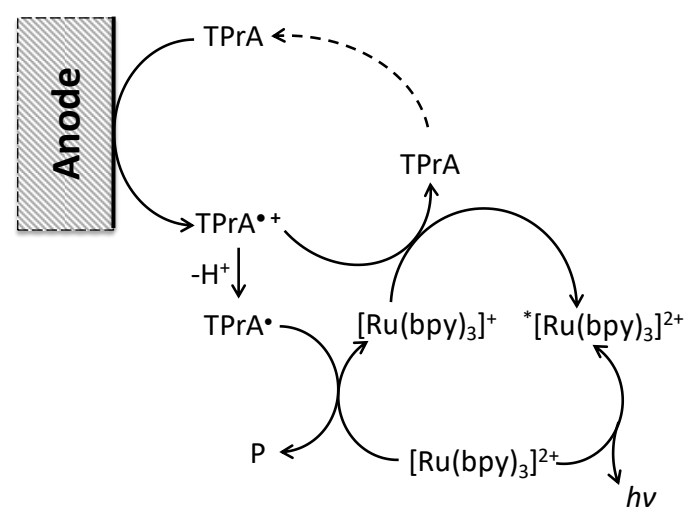

Figure 18. Mechanism of ECL in the $\left[\mathrm{Ru}(\mathrm{bpy})_{3}\right]^{2+}$ tripropylamine (TPrA) system. ${ }^{[79]}$

ECL is extensively used as an analytical technique. ${ }^{[19,79]}$ Compared with fluorescent labels it does not require a light source and is free from effects of scattered light and fluorescent impurities in the sample. Compared with chemiluminescence, ECL can extend the range of analytes detectable with a particular chemiluminescence reaction by transforming electrochemically inactive compounds into co-reactants.

\subsection{Light emitting diodes (LEDs)}

Light-emitting diodes (LEDs) are electronic devices made from a variety of inorganic semiconductor materials (e.g., GaAs, AlGaAs, InGaN) that operate on the principle of electroluminescence. In these devices, electric flow generates electrons and holes. When an electron recombines with a hole, energy can be released in the form of a photon. The applied voltage in most LEDs is quite low, in the region of 2.0 volts; the current depends on the application and ranges from a few milliamperes to several hundred milliamperes. Clearly, LEDs and OLEDs (section 6.4, Figure 19) are based on the same principle of PV cells (Figure 9).

The quantum efficiency of a LED (or OLED) device, given by the ratio of the number of photons emitted divided by the number of electron injected, can be expressed as:

$$
\eta_{\mathrm{LED}}=\eta_{\mathrm{rec}} \eta_{\mathrm{em}} \eta_{\mathrm{ext}}
$$

The first term, $\eta_{\mathrm{rec}}$, is the fraction of electrons and hole that meet to form an exciton. The $\eta_{\mathrm{em}}$ term is the luminescence efficiency of the excited state. The third term, $\eta_{\text {ext, }}$ is the efficiency of light "extraction" from the device to the ambient.

The wavelength of the light emitted, and thus its color, depends on the band gap energy of the materials forming the p-n junction. A single LED emits monochromatic light. White light can be obtained either combining the emissions from individual red, green, and blue LEDs or by using a 
single blue LED whose emission excites a phosphor, which in turn emits white light. This latter design is the most common. The 2014 Nobel Prize in Physics has been awarded to the scientists who have developed gallium nitride $(\mathrm{GaN})$-based materials and devices, including the blue LED. ${ }^{[80]}$

Nowadays, commercial white LEDs have a luminous efficacy in excess of 150 lumen/watt (LPW), much greater than incandescent lamps (12 LPW), or fluorescent lights (80 LPW). ${ }^{[80]}$ Infrared LEDs are employed in autofocus cameras and television remote controls and also as light sources in fiber-optic telecommunication systems. ${ }^{[81]}$

\subsection{Organic light emitting diodes (OLEDs)}

LEDs based on organic compounds or on metal complexes with organic ligands are called organic light-emitting diodes (OLEDs). ${ }^{[82]}$ In a typical OLED device, indium tin oxide (ITO) is utilized as a transparent anode electrode and an evaporated metal is utilized as a cathode. Layers of organic compounds capable of charge transport and light emission are deposited onto the transparent substrate. The injection of electrons is achieved by the use of a low work function metal or an $n$ doped electron injection layer, both of which are unstable in air and require rigorous encapsulation.

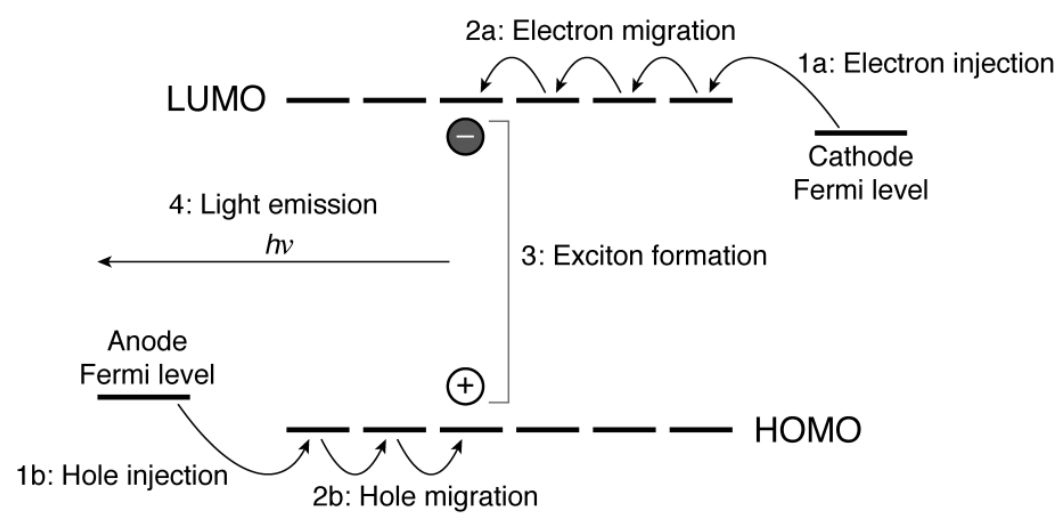

Figure 19. Working principle of an OLED. When a proper bias is applied, anode and cathode Fermi levels are displaced. For details see text.

OLED and OSC devices are related as the LED and PV ones. The four distinct steps occurring in an OLED are illustrated in Figure 19. When a proper bias is applied, electrons (step 1a) and holes (step 1b) are injected. Then, the carriers drift in the presence of the externally applied electric field by hopping from molecule to molecule to the opposite electrode (steps $2 \mathrm{a}$ and $2 \mathrm{~b}$ ). If an electron and a hole happen to meet, they may combine (step 3) to form a molecular excited state 
(exciton) that may deactivate radiatively (step 4) to generate a photon. Compared to LEDs, OLEDs are characterized by a mobility of the charge carriers orders of magnitude lower because the electronic states in organic materials are highly localized.

The color of the emitted light depends, of course, on the energy of the emitting excited state. The most widely used luminescent materials are metal complexes, particularly cyclometallated $\operatorname{Ir}($ III) complexes, which are characterized by very efficient phosphorescence. OLEDs based on purely organic materials would be much cheaper and easier to manufacture. In molecular materials, an electron and a hole can combine to give rise to a singlet or a triplet state, with $25 \%$ and $75 \%$ probability, respectively. ${ }^{[3]}$ Since organic molecules displaying high phosphorescence efficiency in the solid-state are very rare, ${ }^{[83]}$ species capable of exhibiting thermally activated delayed fluorescence (TADF) are used (Figure 20). ${ }^{[8]}$ Fluorescence quantum yield exceeding $90 \%$ and very high external electroluminescence efficiency (about 20\%), comparable to high-efficiency phosphorescence based OLEDs, have recently been achieved. ${ }^{[85]}$

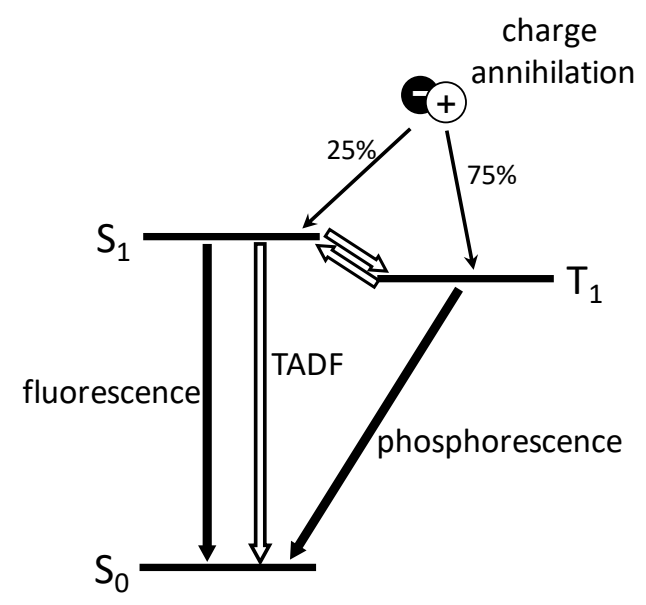

Figure 20. OLEDs light emission. For transition metal complexes, the $S_{1} \rightarrow T_{1}$ intersystem crossing and the radiative decay of $T_{1}$ are very efficient (phosphorescence light emission). For organic molecules, the radiative decay of $T_{1}$ is inefficient and back $T_{1} \rightarrow S_{1}$ intersystem crossing is exploited to obtain TADF.

OLEDs are more expensive and have lower efficiency and shorter lifetime than LEDs. OLEDs are by nature diffuse light sources that are used in displays for mobile phones, portable digital media players, car radios, digital cameras and flat and curved TV screens. Furthermore, they are opening up new perspectives in the field of illumination, such as light tiles, light partition walls, and transparent light sources that emit light only after twilight and act as windows during the day. 
LECs are based on electrochemiluminescence by the annihilation mechanism of mobile ions (Figure 8) applied not to a solution, but to a solid-state device.

Compared to OLEDs, LECs (Figure 21) (i) are characterized by a much simpler architecture, (ii) can be processed from solution, (iii) do not rely on air-sensitive charge-injection layers or metals for electron injection and hence require less stringent packaging procedures.

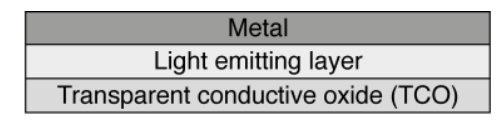

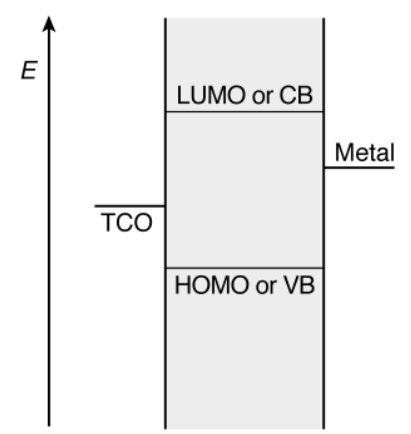

(a)

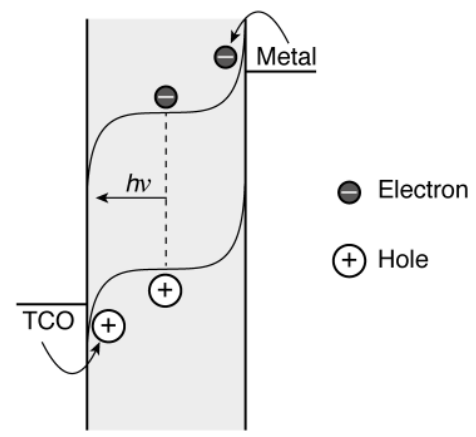

(b)

Figure 21. Schematic representation of a LEC device without (a) and with (b) an applied bias. ${ }^{[3]}$ For more details, see text.

The luminescent material of LECs is either a conjugated light-emitting polymer ${ }^{[86]}$ or an ionic transition metal complex (iTMC). ${ }^{[87,88]}$ Cyclometallated complexes of $\operatorname{Ir}(\mathrm{III})$ are by far the most utilized class of iTMCs in LECs.

For a iTMCLEC based on the metal complex $\mathrm{M}^{\mathrm{n}+}$, upon application of a forward bias the counterions drift towards the anode (ITO), where they accumulate and cause a lowering of the barrier for hole injection in the HOMO of $\mathrm{M}^{\mathrm{n}+}$ with the production of $\mathrm{M}^{(\mathrm{n}+1)+}$. At the same time, the presence of uncompensated $\mathrm{M}^{\mathrm{n}+}$ ions in the neighborhood of the cathode enhances electron injection, which results in the formation of $\mathrm{M}^{(\mathrm{n}-1)+}$. Injected electrons and holes then migrate towards opposite electrodes. Emission results from the recombination of $\mathbf{M}^{(\mathrm{n}+1)+}$ and $\mathbf{M}^{(\mathrm{n}-1)+}$, which produces the excited state $* \mathrm{M}^{\mathrm{n}+}$ of the complex. The details of the reaction mechanism are still the object of discussion. ${ }^{[89]}$

\section{Photosensitization of organic reactions}


The long-standing goal of using sunlight to perform valuable chemical reactions was pursued since Ciamician's time. ${ }^{[39]}$ Since most of organic compounds do not absorb visible light, the interest in this topic for decades was limited to the study of the intimate mechanism of the reactions induced by UV radiation. ${ }^{[1-3]}$ More recently, the use of photosensitizers, particularly semiconductors, has opened the way to the exploitation of sunlight for useful applications. ${ }^{\text {[90-92] }}$

\subsection{Photocatalytic pollution remediation}

Photocatalysts and photosensitizers may strongly enhance the effect of sunlight. Homogeneous and heterogeneous solar photocatalytic detoxification methods are extensively used for the treatment of wastewater and contaminated air. ${ }^{[93,94]} \mathrm{TiO}_{2}$ is by far the most frequently used heterogeneous catalyst for these processes. Reaction of holes with solvent water molecules generates $\mathrm{HO}^{\bullet}$ radicals, whereas electrons are scavenged by molecular oxygen to produce the $\mathrm{O}_{2}{ }^{\circ-}$ ions that then undergo secondary reactions leading to $\mathrm{HO}_{2}{ }^{\circ}$ and $\mathrm{HO}^{\bullet}$ radicals. These radicals can easily attack organic molecules, leading to organic peroxide radicals that eventually convert to $\mathrm{CO}_{2}, \mathrm{H}_{2} \mathrm{O}$ and other non toxic compounds. Since $\mathrm{TiO}_{2}$ can make use only of about $3 \%$ of solar light energy, sensitization toward visible light is the object of active research. ${ }^{[93,94]}$

\subsection{Photosensitization and catalysis in organic synthesis}

In the last few years it has been found that excitation of redox-active coordination compounds (e.g., $\left[\mathrm{Ru}(\mathrm{bpy})_{3}\right]^{2+}$ or $\left.f a c-\left[\operatorname{Ir}(\mathrm{ppy})_{3}\right]\right)$, organic dyes (e.g., eosin $\left.\mathrm{Y}\right)$, or inorganic semiconductors (e.g., CdS) mediates photoinduced electron process to substrates. ${ }^{\text {[93-99] }}$ Excited state redox reactions based on these compounds occur at room temperature, without the need for highly reactive radical initiators.

Photoredox catalysis may be used to develop reactions requiring both the donation and the reception of electrons at disparate points in the reaction mechanism. Furthermore, electron-transfer events often provide access to radical ion intermediates having reactivity patterns fundamentally different from those of their ground electronic or excited states.

Many examples of enantiomerically pure products have been reported either by using a chiral photocatalyst $^{[100]}$ or by decoupling light absorption by the photosensitizer and enantiomeric enrichment by the organocatalyst. ${ }^{[101]}$ 
For space reasons, we will discuss only two prototype photoreactions: those involving either a sacrificial reagent $S$ (Figure 22a) and an organocatalyst Cat (Figure 22b). PS is the photosensitizer, the only species that absorbs in the visible spectral region.

(a)

$$
\mathrm{AX} \underset{\mathrm{VIS} \mathrm{light}}{\stackrel{P}{P}} \mathrm{P}
$$

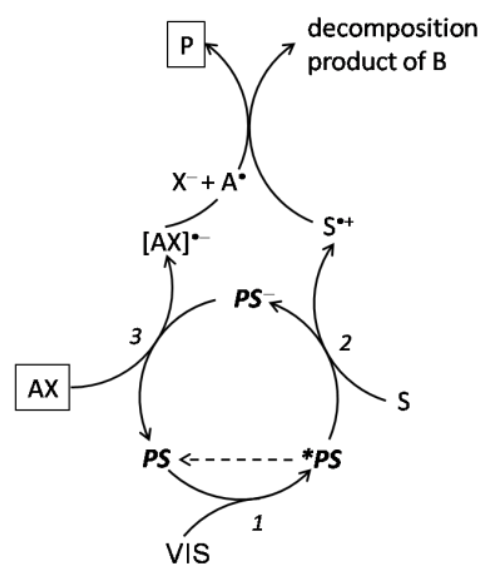

(b) $\quad \mathrm{AX}+\mathrm{B} \frac{\text { PS, Cat }}{\mathrm{VIS} \text { light }} \mathrm{P}$

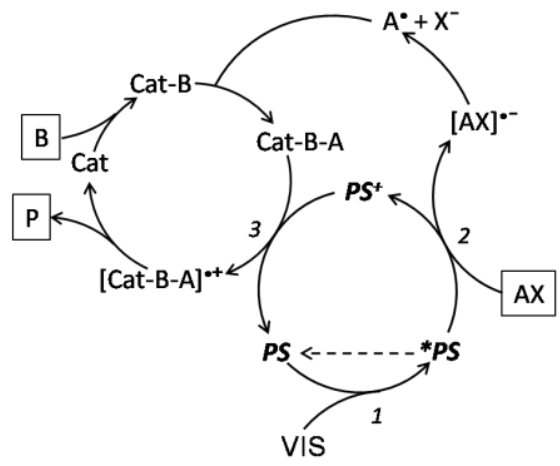

Figure 22. Schematic representation of two prototypes photosensitized organic reactions involving either a sacrificial reagent $\mathrm{S}(\mathrm{a})$ or an organocatalyst Cat (b).

The scheme of Figure 22a is representative, for example, of the reductive de-halogenation in the presence of sacrificial amines: ${ }^{[102]}$ for the easiest to reduce halide compounds, such as activated benzylic or $\alpha$-carbonyl halides, the photosensitizer can be the prototype $\left[\mathrm{Ru}(\mathrm{bpy})_{3}\right]^{2+}$ complex, or in the case of alkyl, alkenyl, and aryl iodides, $f a c$-[ $\left.\operatorname{Ir}(\mathrm{ppy})_{3}\right]$, whose excited state is a much stronger reductant (Figure 3). The sacrificial amine serves to both produce the strong reductant $\mathrm{PS}^{-}$species and to act as a source of hydrogen (similar reactivity to that described for TPrA in Figure 18). An example of the reaction depicted in Figure 22a is the following de-halogenation process:

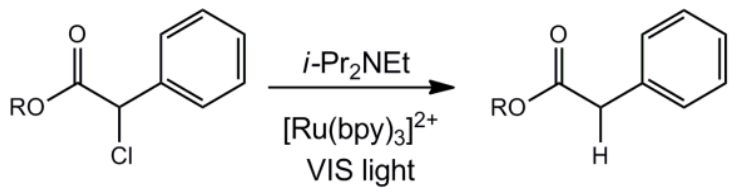

The scheme of Figure 22b illustrates a very elegant example in which a photocatalytic cycle, activated by visible light, has been merged into an organocatalytic cycle without any sacrificial reagent. ${ }^{[103]}$ For example, $\alpha$-benzylation of aldehydes can be performed by this scheme: PS is fac[ $\left.\operatorname{Ir}(\mathrm{ppy})_{3}\right], \mathrm{AX}$ is a benzyl bromide, $\mathrm{B}$ is an aldehyde, Cat is an imidazolidinone organocatalyst, and the product is an $\alpha$-benzyl aldehyde. 


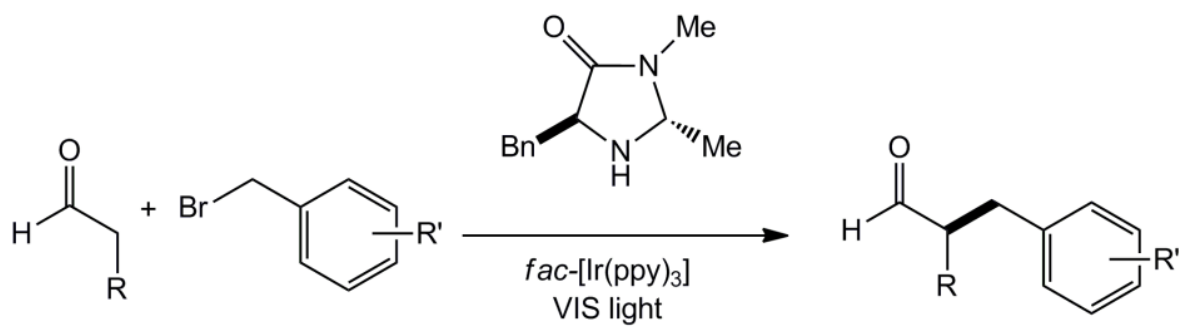

For a rationale and profitable development of sunlight sensitization in organic synthesis, an accurate comprehension of the reaction mechanisms and an evaluation of the efficiencies of the light-induced processes are necessary.

The quantum yield of the photoreaction depends on excited state lifetime, rate of excited state electron transfer reaction, and concentration of the quencher ( $\mathrm{S}$ or Cat in Figure 22a and 22b, respectively). Taking the scheme of Figure $22 \mathrm{a}$ as an example, if the lifetime of *PS in the absence of $\mathbf{S}\left(\tau^{0}\right)$ is $10 \mathrm{~ns}$ in acetonitrile solution at $298 \mathrm{~K}$, the Stern-Volmer equation (Section 2) shows that the minimum concentration of $\mathrm{S}$ required to have $50 \%$ efficiency of process 2 is 5 $\mathrm{mM}$. This example shows that long lifetime is not a strict requisite for photocatalysis in organic synthesis since the concentration of S (Figure 22a) or Cat (Figure 22b) is usually quite high. In the literature, the reaction conditions are often discussed in terms of equivalents of PS with respect to the limiting reagent. However, the efficiency of the reaction depends on the concentration of the species that reacts with the excited state and the rate of the reaction is a function of the light absorbed by PS. Much attention should be devoted to the experimental setup to maximize irradiation (reaction vessel, light flux, irradiation geometry, etc). Most of the papers report reaction conditions in which the PS concentration is extremely high, far beyond the concentration needed for complete absorption of the incident light at the maximum of the absorption band.

In order to compare the ability of different photosensitizers, one should measure the number of moles of product obtained by performing the reaction under the same experimental conditions in terms of concentrations of the reactants and photosensitizers and under simulated sun irradiation.

\section{Conclusion and perspectives}

Mankind is making exaggerated use of the limited resources available on our spaceship Earth. As a result, concern is arising about the energy crisis, ${ }^{[70]}$ the increasing consumption of minerals, ${ }^{[104]}$ the degradation of the environment, ${ }^{[105,106]}$ and climate change. ${ }^{[107]}$ Our finite planet cannot sustain an endless increase of resource consumption and waste production. 
On the other hand, we are making inadequate use of solar energy, an enormous, reliable, practically inexhaustible energy source.

In the present Anthropocene epoch, ${ }^{[108]}$ in which our planet has become more fragile and mankind more powerful than Nature, ${ }^{[109]}$ we are called to take care of spaceship Earth, reversing the present trend characterized by consumerism that converts Earth's resources into waste at an astonishing rate.

Most of the ecological, economic and political problems are related to the exaggerated use of energy, particularly of fossil fuels. Decrease of energy consumption and transition from fossil fuels to renewable energies are the only possible solutions, as indicated by the European Union.

The processes illustrated in this paper, which exploit electron transfer reactions to use sunlight as a reactant and to generate light as a product (Figure 23), can give a determinant contribution both toward the advancement of science and the creation of a more sustainable world.

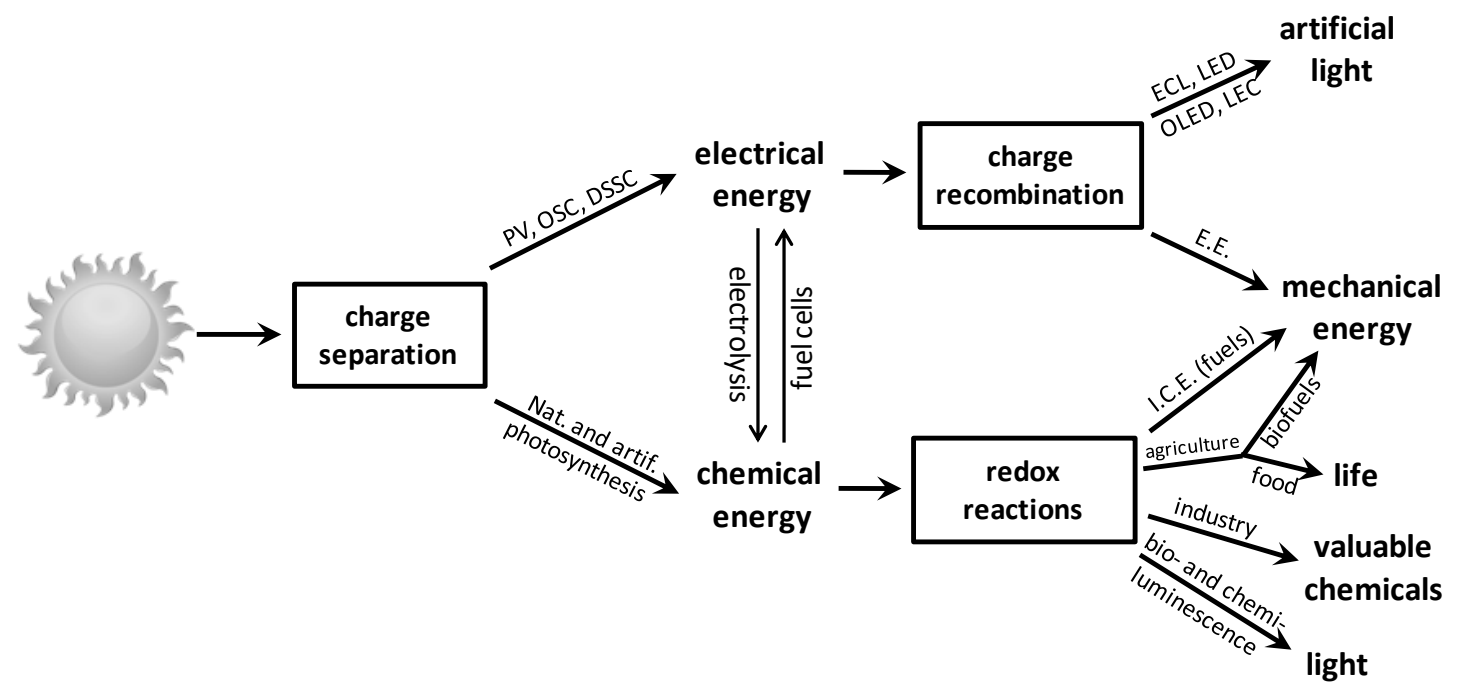

Figure 23. Schematic representation of the sunlight-as-reactant and light-as-product processes discussed in this paper.

Conversion of sunlight into electrical energy by PV cells (Section 4.2) gives already a significant contribution to cover our energy needs (about $160 \mathrm{TWh}$ at the end of 2013, equivalent to the energy produced by about 25 nuclear plants, with over $35 \%$ increase over 2012). ${ }^{[110]}$ The EROEI of PV is significantly increasing and can reach values of $60: 1 .^{[75]}$ The potential of photovoltaic conversion of sunlight is indeed enormous. ${ }^{[74]}$ A detailed study concerning the European Union showed that covering $\sim 0.6 \%$ of the European territory by current PV modules would theoretically satisfy its entire electricity demand. ${ }^{[111]}$ Higher efficiency, better stability and use of more abundant and less expensive materials in organic solar cells (OSCs, Section 4.3) and dye- 
sensitized solar cells (DSSCs, Section 4.4) are likely to give a significant contribution to cost decrease and production increase of photovoltaic electricity in the next few years. The electrical energy produced by sunlight, of course, has a number of useful applications. Once stored in batteries, it can be used to power electric engines (EE), whose efficiency is about four times higher than the efficiency of internal combustion engines (ICE). For long-time storage, electric energy can be converted into hydrogen by electrolysis and then reconverted into electricity by fuel cells, even on board of vehicles to power electric engines. ${ }^{[70]}$

The generation of light by electrochemiluminescence (Section 6.2) is extensively used for analytical purposes in medicine, environment, and several other fields. The very efficient conversion of electrical energy into light by LEDs (Sections 6.3) has allowed replacing incandescent light bulbs, with a substantial reduction of energy consumption for lightening. Furthermore, LEDs are increasingly used in medicine, education, data transmission, machine vision systems (e.g., barcode scanners) and a variety of other applications. The use of OLEDs (Section 6.4) for all kinds of displays is being developed by the major electronic industries.

Conversion of solar energy into chemical energy (Section 5) is a more difficult task than conversion into electrical energy because it implies storage of the converted energy. The efficiency of natural photosynthesis is very low and not easy to improve. Therefore, biofuels can give only a marginal contribution to replace hydrocarbon fuels. Furthermore, they are in competition with food and do not contribute appreciably to reduction of greenhouse emissions.

Artificial photosynthesis (Section 5.2) represents an important breakthrough but it is still at its early research and development stage and will give a contribution to energy supply only when its current limitations concerning efficiency, stability and scalability are overcome.

Besides generation of solar fuels, solar photochemistry can be exploited for other purposes, including pollution remediation and synthesis of valuable products (Section 7). Several high value chemical products have been prepared starting from common reagents, but we are still far from fulfilling Ciamician's dream: “On the arid lands there will spring up industrial colonies without smoke; forests of glass tubes will extend over the plains and glass buildings will rise everywhere; inside of these will take place the photochemical processes that up until now have been the guarded secret of the plants, but that will have been mastered by human industry which will know how to make them bear even more abundant fruit than nature, for nature is not in a hurry and mankind is." Nevertheless, such a grand vision should not be left aside. Hopefully, scientists engaged in the exploitation of sunlight, a really unique reactant (plentiful, inexhaustible, available everywhere and very energetic), will succeed in devising processes capable of fabricating valuable products starting from materials such as seawater, the components of our atmosphere 
(oxygen, nitrogen, carbon dioxide), and abundant minerals. Natural photosynthesis, artificial photochemical water splitting, photochemical reduction of carbon dioxide to methanol and, very recently, production of isopropanol by an integrated bioelectrochemical system based on an engineered bacterium, ${ }^{[112]}$ and the photochemical nitrogen fixation assisted by visible light ${ }^{[113-115]}$ suggest indeed that one day Ciamician' dream ${ }^{[39]}$ could become true. ${ }^{[116,117]}$

Acknowledgments. We gratefully acknowledge the European Commission ERC Starting Grant (PhotoSi, 278912).

\section{References}

[1] P. Klán, J. Wirz, Photochemistry of Organic Compounds: From Concepts to Practice, Wiley, Chichester, 2009.

[2] N. J. Turro, V. Ramamurthy, J. C. Scaiano, Modern Molecular Photochemistry of Organic Molecules, University Science Books, Sausalito, 2010.

[3] V. Balzani, P. Ceroni, A. Juris, Photochemistry and Photophysics: Concepts, Research, Applications, Wiley-VCH, Weinheim, 2014.

[4] G. Ciamician, Bull. Soc. Chim. Fr. [4] 1908, 3, i- xxvii.

[5] L. Pause, M. Robert, J.-M. Savéant, J. Am. Chem. Soc. 1999, 121, 7158-7159.

[6] V. Balzani, A. Juris, Coord. Chem. Rev. 2001, 211, 97-115.

[7] V. Balzani, F. Scandola, Supramolecular Photochemistry, Horwood, New York, 1991.

[8] A. Juris, V. Balzani, F. Barigelletti, S. Campagna, P. Belser, A. von Zelewsky, Coord. Chem. Rev. 1988, 84, 85-277.

[9] M. Maestri, V. Balzani, C. Deuschel-Cornioley, A. von Zelewsky, Adv. Photochem. 1992, 17, 1-68.

[10] L. Flamigni, A. Barbieri, C. Sabatini, B. Ventura, F. Barigelletti, Top. Curr. Chem. 2007, 281, 143-204.

[11] K. Kalyanasundaram, Photochemistry of Polypyridine and Porphyrin Complexes, Academic Press, London, 1992.

[12] V. Balzani, A. Credi, M. Venturi, Molecular Devices and Machines: Concepts and Perspectives for the Nanoworld, Wiley-VCH, Weinheim, 2008.

[13] A. P. de Silva, Molecular Logic-Based Computation, RSC Publishing, Cambridge, 2013.

[14] P. Ceroni, G. Bergamini, V. Balzani, Angew. Chem. Int. Ed. 2009, 48, 8516-8518.

[15] V. Balzani, F. Bolletta, M. Ciano, M. Maestri, J. Chem. Educ. 1983, 60, 447-450.

[16] R. C. Young, T. J. Meyer, D. G. Whitten, J. Am. Chem. Soc. 1975, 97, 4781-4782.

[17] C.-T. Lin, N. Sutin, J. Phys. Chem. 1976, 80, 97-105.

[18] I. Rubinstein, A. J. Bard, J. Am. Chem. Soc. 1981, 103, 512-516.

[19] A. J. Bard, Ed., Electrogenerated Chemiluminescence, Marcel Dekker, Inc., New York, 2004.

[20] W. Shockley, H. J. Queisser, J. Appl. Phys. 1961, 32, 510-519.

[21] "National Renewable Energy Laboratory: best research-cell efficiencies," can be found under http://www.nrel.gov/ncpv/images/efficiency_chart.jpg, 2014.

[22] C. Wadia, A. P. Alivisatos, D. M. Kammen, Environ. Sci. Technol. 2009, 43, 2072-2077.

[23] D. F. Kronholm, J. C. Hummelen, in Org. Photovoltaics Mater. Device Physics, Manuf. Technol. (Eds.: C. Brabec, V. Dyakonov, U. Scherf), Wiley-VCH, Weinheim, 2008. 
[24] T. Liu, A. Troisi, Adv. Mater. 2013, 25, 1038-41.

[25] M. T. Dang, L. Hirsch, G. Wantz, J. D. Wuest, Chem. Rev. 2013, 113, 3734-3765.

[26] R. J. Janssen, J. Nelson, Adv. Mater. 2013, 25, 1847-58.

[27] B. O’Regan, M. Graetzel, Nature 1991, 353, 737-740.

[28] C. a. Bignozzi, R. Argazzi, R. Boaretto, E. Busatto, S. Carli, F. Ronconi, S. Caramori, Coord. Chem. Rev. 2013, 257, 1472-1492.

[29] S. Mathew, A. Yella, P. Gao, R. Humphry-Baker, C. F. E., N. Ashari-Astani, I. Tavernelli, U. Rothlisberger, N. Khaja, M. Grätzel, Nat. Chem. 2014, 6, 242-247.

[30] A. Nattestad, A. J. Mozer, M. K. R. Fischer, Y.-B. Cheng, A. Mishra, P. Bauerle, U. Bach, Nat. Mater. 2010, 9, 31-35.

[31] S. D. Stranks, P. K. Nayak, W. Zhang, T. Stergiopoulos, H. J. Snaith, Angew. Chem. Int. Ed. 2015, 54, 3240-3248.

[32] F. Hao, C. C. Stoumpos, D. H. Cao, R. P. H. Chang, M. G. Kanatzidis, Nat. Photon. 2014, 8, 489-494.

[33] S. N. Habisreutinger, T. Leijtens, G. E. Eperon, S. D. Stranks, R. J. Nicholas, H. J. Snaith, Nano Lett. 2014, 14, 5561-5568.

[34] R. E. Blankenship, Molecular Mechanisms of Photosynthesis, Blackwell Science, Oxford, 2002.

[35] M. Suga, F. Akita, K. Hirata, G. Ueno, H. Murakami, Y. Nakajima, T. Shimizu, K. Yamashita, M. Yamamoto, H. Ago, et al., Nature 2015, 517, 99-103.

[36] P. E. M. Siegbahn, Acc. Chem. Res. 2009, 42, 1871-1880.

[37] H. Michel, Angew. Chem. Int. Ed. 2012, 51, 2516-2518.

[38] J. Barber, P. D. Tran, J. R. Soc. Inter. 2013, 10.

[39] G. Ciamician, Science 1912, 36, 385-394.

[40] S. N. Habisreutinger, L. Schmidt-Mende, J. K. Stolarczyk, Angew. Chem. Int. Ed. 2013, 52, 7372-7408.

[41] C. D. Windle, R. N. Perutz, Coord. Chem. Rev. 2012, 256, 2562-2570.

[42] A. J. Morris, G. J. Meyer, E. Fujita, Acc. Chem. Res. 2009, 42, 1983-1994.

[43] V. Balzani, L. Moggi, M. F. Manfrin, F. Bolletta, M. Gleria, Science 1975, 189, 852-856.

[44] D. R. Weinberg, C. J. Gagliardi, J. F. Hull, C. F. Murphy, C. A. Kent, B. C. Westlake, A. Paul, D. H. Ess, D. G. McCafferty, T. J. Meyer, Chem. Rev. 2012, 112, 4016-4093.

[45] A. Migliore, N. F. Polizzi, M. J. Therien, D. N. Beratan, Chem. Rev. 2014, 114, 3381-3465.

[46] S. Campagna, P. Ceroni, F. Puntoriero, Eds., Designing Dendrimers, Wiley, Hoboken, 2012.

[47] V. Garg, G. Kodis, M. Chachisvilis, M. Hambourger, A. L. Moore, T. A. Moore, D. Gust, J. Am. Chem. Soc. 2011, 133, 2944-2954.

[48] B. Sherman, M. Vaughn, J. Bergkamp, D. Gust, A. Moore, T. Moore, Photosynth. Res. 2014, $120,59-70$.

[49] S. Berardi, S. Drouet, L. Francas, C. Gimbert-Surinach, M. Guttentag, C. Richmond, T. Stoll, A. Llobet, Chem. Soc. Rev. 2014, 43, 7501-7519.

[50] A. Sartorel, M. Bonchio, S. Campagna, F. Scandola, Chem. Soc. Rev. 2013, 42, 2262-2280.

[51] C. R. Cox, J. Z. Lee, D. G. Nocera, T. Buonassisi, Proc. Natl. Acad. Sci. 2014, 111, 1405714061.

[52] M. Carmo, D. L. Fritz, J. Mergel, D. Stolten, Int. J. Hydrog. En. 2013, 38, 4901-4934.

[53] Y. Qu, X. Duan, Chem. Soc. Rev. 2013, 42, 2568-2580.

[54] X. Li, J. Yu, J. Low, Y. Fang, J. Xiao, X. Chen, J. Mater. Chem. A 2015, 3, 2485-2534.

[55] T. Hisatomi, J. Kubota, K. Domen, Chem. Soc. Rev. 2014, 43, 7520-7535.

[56] A. Fujishima, K. Honda, Nature 1972, 238, 37-38.

[57] J. Ran, J. Zhang, J. Yu, M. Jaroniec, S. Z. Qiao, Chem. Soc. Rev. 2014, 43, 7787-7812.

[58] L. Liao, Q. Zhang, Z. Su, Z. Zhao, Y. Wang, Y. Li, X. Lu, D. Wei, G. Feng, Q. Yu, et al., Nat Nano 2014, 9, 69-73.

[59] A. J. Bard, J. Photochem. 1979, 10, 59-75. 
[60] H. Tada, T. Mitsui, T. Kiyonaga, T. Akita, K. Tanaka, Nat. Mater. 2006, 5, 782-786.

[61] B. Liu, C.-H. Wu, J. Miao, P. Yang, ACS Nano 2014, 8, 11739-11744.

[62] S. Y. Reece, J. A. Hamel, K. Sung, T. D. Jarvi, A. J. Esswein, J. J. H. Pijpers, D. G. Nocera, Science 2011, 334, 645-648.

[63] J. Luo, J.-H. Im, M. T. Mayer, M. Schreier, M. K. Nazeeruddin, N.-G. Park, S. D. Tilley, H. J. Fan, M. Grätzel, Science 2014, 345, 1593-1596.

[64] J. R. McKone, N. S. Lewis, H. B. Gray, Chem. Mater. 2014, 26, 407-414.

[65] S. Protti, A. Albini, N. Serpone, Phys. Chem. Chem. Phys. 2014, 16, 19790-19827.

[66] Z. Yu, F. Li, L. Sun, En. Environ. Sci. 2015, 8, 760-775.

[67] W. J. Youngblood, S.-H. A. Lee, Y. Kobayashi, E. A. Hernandez-Pagan, P. G. Hoertz, T. A. Moore, A. L. Moore, D. Gust, T. E. Mallouk, J. Am. Chem. Soc. 2009, 131, 926-927.

[68] Y. Zhao, J. R. Swierk, J. D. Megiatto, B. Sherman, W. J. Youngblood, D. Qin, D. M. Lentz, A. L. Moore, T. A. Moore, D. Gust, et al., Proc. Natl. Acad. Sci. 2012, 109, 15612-15616.

[69] S. Bensaid, G. Centi, E. Garrone, S. Perathoner, G. Saracco, ChemSusChem 2012, 5, 500521.

[70] N. Armaroli, V. Balzani, Energy for a Sustainable World: From the Oil Age to a SunPowered Future, Wiley-VCH, Weinheim, 2011.

[71] R. E. Blankenship, D. M. Tiede, J. Barber, G. W. Brudvig, G. Fleming, M. Ghirardi, M. R. Gunner, W. Junge, D. M. Kramer, A. Melis, et al., Science 2011, 332, 805-809.

[72] J. Woods, A. Williams, J. K. Hughes, M. Black, R. Murphy, Phil. Trans. R. Soc. London B Biol. Sci. 2010, 365, 2991-3006.

[73] D. Charles, Science 2009, 324, 587.

[74] D. Fürstenwerth, Current and Future Cost of Photovoltaics, 2015.

[75] V. Fthenakis, Mag. Prof. Enginers 2012, 16-17.

[76] A. Roda, M. Guardigli, Anal. Bioanal. Chem. 2012, 402, 69-76.

[77] "Bioluminescence," can be found under http://www.lifesci.ucsb.edu/ biolum/, 2015.

[78] F. Bolletta, V. Balzani, J. Am. Chem. Soc. 1982, 104, 4250-4251.

[79] L. Hu, G. Xu, Chem. Soc. Rev. 2010, 39, 3275-3304.

[80] P. Von Dollen, S. Pimputkar, J. S. Speck, Angew. Chem. Int. Ed. 2014, 53, 13978-13980.

[81] G. Held, Introduction to Light Emitting Diode Technology and Applications, CRC Press, Boca Raton, 2009.

[82] A. Buckley, Ed., Organic Light-Emitting Diodes (OLEDs): Materials, Devices and Applications, Woodhead Publishing Limited, Cambridge, 2013.

[83] G. Bergamini, A. Fermi, C. Botta, U. Giovanella, S. Di Motta, F. Negri, R. Peresutti, M. Gingras, P. Ceroni, J. Mater. Chem. C 2013, 1, 2717-2724.

[84] Y. Tao, K. Yuan, T. Chen, P. Xu, H. Li, R. Chen, C. Zheng, L. Zhang, W. Huang, Adv. Mater. 2014, 26, 7931-7958.

[85] H. Uoyama, K. Goushi, K. Shizu, H. Nomura, C. Adachi, Nature 2012, 492, 234-8.

[86] Q. Pei, G. Yu, C. Zhang, Y. Yang, A. J. Heeger, Science 1995, 269, 1086 - 1088.

[87] K. M. Maness, R. H. Terrill, T. J. Meyer, R. W. Murray, R. M. Wightman, J. Am. Chem. Soc. 1996, 118, 10609-10616.

[88] R. D. Costa, E. Ortí, H. J. Bolink, F. Monti, G. Accorsi, N. Armaroli, Angew. Chem. Int. Ed. 2012, 51, 8178-8211.

[89] G. G. Malliaras, J. D. Slinker, J. A. DeFranco, M. J. Jaquith, W. R. Silveira, Y.-W. Zhong, J. M. Moran-Mirabal, H. G. Craighead, H. D. Abruna, J. A. Marohn, Nat. Mater. 2008, 7, 168.

[90] N. Hoffmann, ChemSusChem 2012, 5, 352-371.

[91] D. Ravelli, M. Fagnoni, A. Albini, Chem. Soc. Rev. 2013, 42, 97-113.

[92] D. Spasiano, R. Marotta, S. Malato, P. Fernandez-Ibanez, I. Di Somma, Appl. Catal. B 2015, 170, 90-123.

[93] H. Kisch, Angew. Chem. Int. Ed. 2013, 52, 812-847.

[94] H. Kisch, Semiconductor Photocatalysis, Wiley-VCH, Weinheim, Germany, n.d. 
[95] J. W. Tucker, C. R. J. Stephenson, J. Org. Chem. 2012, 77, 1617-1622.

[96] C. K. Prier, D. A. Rankic, D. W. C. MacMillan, Chem. Rev. 2013, 113, 5322-5363.

[97] C. Wang, Z. Lu, Org. Chem. Front. 2015, 2, 179-190.

[98] D. M. Schultz, T. P. Yoon, Science 2014, 343, DOI 10.1126/science. 1239176.

[99] M. Peña-López, A. Rosas-Hernández, M. Beller, Angew. Chem. Int. Ed. 2015, 54, 50065008.

[100] H. Huo, X. Shen, C. Wang, L. Zhang, P. Rose, L.-A. Chen, K. Harms, M. Marsch, G. Hilt, E. Meggers, Nature 2014, 515, 100-103.

[101] J. Du, K. L. Skubi, D. M. Schultz, T. P. Yoon, Science 2014, 344, 392-396.

[102] J. M. R. Narayanam, J. W. Tucker, C. R. J. Stephenson, J. Am. Chem. Soc. 2009, 131, 87568757.

[103] D. A. Nicewicz, D. W. C. MacMillan, Science 2008, 322, 77-80.

[104] U. Bardi, Extracted: How the Quest for Mineral Wealth Is Plundering the Planet, Chelsea Green, 2014.

[105] L. R. Brown, World on the Edge: How to Prevent Environmental and Economic Collapse, Norton, New York, 2011.

[106] "Global Footprint Network (2011), Annual Report 2011," can be found under http://issuu.com/globalfootprintnetwork/docs/gfn_ar_2013_final/1, 2014.

[107] "Fifth Assessment Report: Climate Change," can be found under http://www.ipcc.ch/report/ar5/syr/, 2014.

[108] P. J. Crutzen, Nature 2002, 415, 23.

[109] V. Balzani, Tox. Environ. Chem. n.d., 0, 1-5.

[110] "European Photovoltaic Industry Association," can be found under http://www.epia.org/home/, n.d.

[111] M. Šúri, T. A. Huld, E. D. Dunlop, H. A. Ossenbrink, Sol. Energy 2007, 81, 1295-1305.

[112] J. P. Torella, C. J. Gagliardi, J. S. Chen, D. K. Bediako, B. Colón, J. C. Way, P. A. Silver, D. G. Nocera, Proc. Natl. Acad. Sci. USA 2015, 112, 201424872.

[113] T. Miyazaki, H. Tanaka, Y. Tanabe, M. Yuki, K. Nakajima, K. Yoshizawa, Y. Nishibayashi, Angew. Chem. Int. Ed. 2014, 53, 11488-11492.

[114] H. Li, J. Shang, Z. Ai, L. Zhang, J. Am. Chem. Soc. DOI: 10.1021/jacs.5b03105.

[115] A. Banerjee, B. D. Yuhas, E. A. Margulies, Y. Zhang, Y. Shim, M. R. Wasielewski, M. G. Kanatzidis, J. Am. Chem. Soc. 2015, 137, 2030-2034.

[116] P. Ceroni, A. Credi, M. Venturi, V. Balzani, Photochem. Photobiol. Sci. 2010, 9, 1561-1573.

[117] H. B. Gray, Nat. Chem. 2009, $1,7$. 